\title{
How Important Is Health Inequality for Lifetime Earnings Inequality?
}

\author{
Roozbeh Hosseini, Karen Kopecky, and Kai Zhao
}

\author{
Working Paper 2021-1a \\ January 2021 (Revised November 2021)
}

\begin{abstract}
We study the effect of poor health on labor supply and its implications for lifetime earnings inequality. Using a dynamic panel approach, we provide empirical evidence that negative health shocks significantly reduce earnings. The effect is primarily driven by the participation margin and is concentrated among the less educated and those in poor health. Next, we develop a life cycle model of labor supply featuring risky and heterogeneous health profiles that affect individuals' productivity, likelihood of access to social insurance, disutility from work, mortality, and medical expenses. Individuals can either work or not work and apply for social security disability insurance (SSDI/SSI). Eliminating health inequality in our model reduces the variance of log lifetime (accumulated) earnings by 30 percent at age 65 . About twothirds of this effect is due to the impact of poor health on the probability of obtaining SSDI/SSI benefits. Despite this, we show that eliminating the SSDI/SSI program reduces ex ante welfare.
\end{abstract}

JEL classification: D52, D91, E21, H53, I13, I18

Key words: earnings, health, frailty, inequality, disability, dynamic panel estimation, life-cycle models https://doi.org/10.29338/wp2021-1a

The authors thank Jordan Herring for outstanding research assistance. They are grateful to Hannes Schwandt and David Wiczer for insightful discussions. They thank R. Anton Braun, Mariacristina De Nardi, Eric French, Dirk Krueger, Hamish Low, Kjetil Storessletten, and Richard Rogerson for feedback. They also thank attendees at the IFS conference on Inequality and Transfers over the Life Cycle, the Federal Reserve Bank of San Francisco conference on Micro-Macro Labor Economics, Barcelona GSE Summer Forum, MRDRC Researcher Workshop, Shanghai Macro Workshop, SED, Midwest Macro, and SEA meetings as well as seminar participants at the Bank of Canada, Purdue, PHBS, UAB-IAE, UCSB, University of Hawaii, University of Minnesota, McMaster University, USC Marshall School, University of Alabama, the Federal Reserve Bank of Philadelphia, Vanderbilt, William and Mary, University of Houston, and University of Tokyo. See the online appendix for supplemental material. The views expressed here are those of the authors and not necessarily those of the Federal Reserve Bank of Atlanta or the Federal Reserve System. Any remaining errors are the authors' responsibility.

Please address questions regarding content to Roozbeh Hosseini, University of Georgia/Federal Reserve Bank of Atlanta, roozbeh@uga.edu; Karen Kopecky, Federal Reserve Bank of Atlanta/Emory University, karen.kopecky@atl.frb.org; or Kai Zhao, University of Connecticut, kai.zhao@uconn.edu.

Federal Reserve Bank of Atlanta working papers, including revised versions, are available on the Atlanta Fed's website at www.frbatlanta.org. Click "Publications" and then "Working Papers." To receive e-mail notifications about new papers, use frbatlanta.org/forms/subscribe. 


\section{Introduction}

Poor health affects individuals in multiple ways. It reduces their potential earning ability. It increases their cost of working, their mortality, and their medical expenses. It also increases their likelihood of accessing social insurance programs such as Social Security Disability Insurance (SSDI) and Supplemental Security Income (SSI). In this paper we quantify the impact of health inequality on inequality in lifetime earnings. In particular, we assess how much of the variation in lifetime earnings among older individuals in the United States is due to the fact that they have faced heterogeneous and risky health events over their life cycles. We also assess the relative contributions of the various channels through which health impacts individuals.

We start our analysis by showing empirically that health shocks have a large impact on earnings and hours worked. The effect operates primarily through the participation margin and is concentrated among less educated and poor health individuals. Given these findings, we develop and calibrate a life cycle model of labor supply. Individuals in the model have risky heterogeneous health profiles that impact their productivity, disutility from work, medical expenses, mortality, and likelihood of successfully becoming SSDI or SSI (DI) recipients. They make decisions on whether to work, or stay out of labor force and try their luck at getting DI benefits.

To quantify the impact of health inequality on lifetime earnings inequality we use the calibrated model to conduct the following exercise. We collapse all heterogeneity in health by giving every agent in the economy the average health profile. In this counterfactual economy, by age 65 , the variance of log lifetime earnings (measured as the sum of all past earnings) is 30 percent lower relative to benchmark. A decomposition exercise reveals that two-thirds of this decline is due to the effect of poor health on the likelihood of receiving DI benefits. Other factors, such as the impact of health on productivity and disutility from work are less important.

Having found that the DI program is the primary channel through which health inequality generates lifetime earnings inequality, we then ask whether individuals in our model economy would be better off without it. We find that, even though the DI program increases lifetime earnings inequality, it is welfare improving. Together with the tax implications of rebalancing the government budget, long-run ex ante welfare falls by 1.8 percent if the program is removed.

Our analysis employs a new objective measure of health status, called the frailty index. ${ }^{1}$ The frailty index is simply the accumulated sum of all adverse health events that an individual has incurred. Each health problem is referred to as a deficit. In Hosseini et al. (forthcoming), we show that the index is highly predictive of future health-related events (such as mortality, or entry into nursing home). One advantage of the frailty index is that unlike other common health indicators (such as self-reported health status) it is an objective measure of health and comparable across datasets. A feature we exploit in our calibration. Another advantage is that it measures health and its variation on a fine scale. This feature is important because it is the variation in health among already unhealthy individuals, those in

\footnotetext{
${ }^{1}$ We are not the first study that uses the frailty index as a measure of health status. See Dalgaard and Strulik (2014), Schünemann et al. (2017b), and Schünemann et al. (2017b,a) for other instances.
} 
the upper tail of the frailty distribution, that drives variation in earnings and labor supply.

The fact that we can measure frailty on a fine scale also means that we can treat it as a continuous variable. In our empirical analysis, we use the Panel Study of Income Dynamics (PSID) and a dynamic panel data approach (see Blundell and Bond (1998)) to estimate the marginal effects of changes in frailty on earnings, hours worked, and wages. We find that incurring one additional deficit reduces earnings and hours worked by 20 and 14 percent, respectively. We find no statistically significant effect on hours conditional on working and relatively small effects on wages indicating that the effects are driven by the employment margin. We then use our dynamic panel estimator to estimate the causal effect of changes in earnings on frailty. Controlling for age and fixed effects, we fail to find statistically significant effects both overall and, on average, within the education and health groups we consider.

We use these empirical findings to guide the development of our structural model. Since we do not find statistically significant effects of earnings on frailty, we do not allow for such feedback effects in the model. However, we do allow life-cycle frailty dynamics to differ by education which is important because, as we document in Hosseini et al. (forthcoming), these differences are substantial. In addition to frailty risk, individuals in the model face both productivity and employment risk. They jointly make consumption, savings, and labor supply decisions in each period over their life cycle. Given our empirical findings, we assume that individuals in the model only adjust labor supply on the extensive margin. Workingage individuals can choose to work or exit the labor force and apply for disability insurance. Retirement-age individuals can choose to work or retire. Markets are incomplete, but there exists a government that runs the DI program, as well as, a social security program and a tax/transfer system.

An individual's frailty affects their behavior through five different channels: mortality rates, out-of-pocket medical expenditures, labor productivity, probability of successful DI application, and disutility from working. We estimate the effect of frailty on the first three directly from the data. In particular, we estimate the effect of frailty on mortality using the Health and Retirement Study (HRS) and the effect of frailty on out-of-pocket medical expenditures using the Medical Expenditures Panel Survey (MEPS). When estimating the effect of frailty on productivity it is important to control for selection due to non-participation. Thus, we use PSID and our dynamic panel data estimator together with a selection correction procedure proposed by Al-Sadoon et al. (2019).

We estimate the dependence of the probability of DI success and disutility from work on frailty using the model and a simulated method of moments procedure. We use two sets of empirical targets that allows us to separately identify these two channels. The first set consists of DI recipiency rates by various frailty percentile groups for 5 -year age groups between 25 and 64 . The second set is labor force participation rates by frailty percentile groups for 5-year age groups between 25 and 84 . Both the DI recipiency rates and labor force participation rates of individuals younger than 65 are affected by disutility from work and DI success probabilities. However, those who are older than 65 are not eligible for DI. Therefore, the observed variation in labor force participation by frailty for those older than 65 must be due to the effect of frailty on disutility of work. By targeting this variation, we are able to separate out effects of frailty operating through the disutility channel from those that operate through DI.

To assess the quality of our baseline calibration we use a set of non-targeted moments. 
The moments we focus on are the variation in labor force participation rates and DI recipiency rates by education. We have three education groups in the model: high school dropouts, high school graduates, and college graduates. We compare both the aggregate labor force participation rates and DI recipiency rates by education in the model to the data and the variation in these rates by frailty and age within each education group. The model is able to replicate the patterns in these rates observed in the data. To further assess the calibration, we compare the labor force participation rates of individuals who are denied DI benefits in the model to estimates from the empirical literature. In the model, 31 percent of individuals who are denied benefits in their first year of application are working three years later. Comparable estimates in the literature range from 26 to 35 percent (see, for instance, French and Song (2014) among others) .

Removing all heterogeneity in health by giving every agent in the baseline economy the average frailty profile lowers the variance of log lifetime earnings for each age group 40 and older. The difference peaks at age 65 when the decline is 30 percent. However, the impacts on lifetime earnings inequality are sizable at all ages after age 40 . For instance, lifetime earnings inequality declines by 13 percent at age 45, 27 percent at age 55, and 24 percent at age 75 . Inspection of the ratios of lifetime earnings at the 5th, 10th, 90th and 95th percentiles relative to the median reveals that the effects of frailty inequality on earnings inequality are concentrated in the bottom of the earnings distribution. Frailty heterogeneity in the baseline economy is due to both initial fixed heterogeneity and frailty shocks. Decomposing the relative roles of shocks versus fixed effects, reveals that shocks play a relatively more important role. At age 65, they are responsible for about two-thirds of the total impact of health heterogeneity on the lifetime earnings distribution.

To decompose the effect of health inequality into the various channels through which frailty operates in the model we conduct a series of counterfactual exercises. In each experiment we turn off the effect of frailty only in one channel. For example, in our first counterfactual exercise, we assume the probability of DI award does not depend on an agent's individual frailty, but rather depends on the average frailty profile. We find that, at younger ages, the decline in lifetime earnings inequality when we remove health inequality is primarily due to the labor productivity channel. However, at older ages, it is primarily due to the impact of frailty on the probability of DI receipt. Relative to the labor productivity and DI channels, the other three channels have a relatively small impact. In particular, the effect of frailty on disutility of work does not seem to be an important determinant of how health affects labor supply and earnings inequality.

The reason why the primary channel through which health inequality operates differs by age is as follows. Using the average frailty profile to determine individuals' labor productivity reduces lifetime earnings inequality at all ages. In contrast, assuming that DI eligibility is determined by the average frailty profile has two effects. One, it reduces the incentive for frail young individuals to work. They no longer have a high probability of getting on DI when older. Thus, instead of accumulating lifetime earnings to increase their expected future DI benefits, they prefer to avoid the disutility of work and rely on means-tested welfare programs. Two, it increases the labor supply of older frail individuals. These individuals no longer have a high probability of getting DI either, but, because they have more accumulated wealth, they are less likely to obtain means-tested benefits if they stop working. Thus, they prefer to work until retirement age. The importance of the second effect grows larger with 
age making the DI channel the most important channel through which health inequality increases lifetime earnings inequality from age 55 on.

Despite increasing aggregate output and consumption and reducing earnings inequality, we find the the DI program is welfare improving. The ex ante welfare loss from removing the program is due to highly frail less educated workers who have low labor productivity and high disutility from work. Without the DI program, they choose between increased dependence on means-tested transfers for consumption or working more despite the high utility costs and relatively low returns. College graduates welfare increases because their tax contributions to the program primarily subsidize less educated individuals and the welfare costs of this redistribution outweigh the insurance value of the program for them. Given these findings, we ask whether agents in our model would prefer a DI program that does not allow for redistribution across education groups. Interestingly, we find that if income taxes do not adjust, such a program is highly valued by college graduates. However, requiring each education group to finance their own DI program leads to increased reliance by less educated individuals on means-tested transfers which raise income taxes. Once taxes adjust, the policy reform leaves all education groups worse off.

\section{$1.1 \quad$ Related Literature}

Our paper belongs to a growing literature that uses rich life cycle models to study the aggregate and distributional economic impacts of health and health expenditures. See, for instance, French (2005), De Nardi et al. (2010), De Nardi et al. (2017), Suen (2006), Capatina (2015), Kopecky and Koreshkova (2014), Zhao (2014), Ozcan (2013), Braun et al. (2017), Capatina et al. (2020), French and Jones (2017), Imrohoroglu and Zhao (2018), and Prados (2017), among others. One notable example is Nygaard (2021) who uses the frailty index in a structural model to study inequality in life expectancy.

There are several related papers that study the DI program. Low and Pistaferri (2015) use a life cycle model to study the impact of reforms to SSDI and means-tested welfare programs on welfare and behavior. Our findings on the welfare implications of cutting/raising SSDI benefits by 10 percent are consistent with their analysis. Kitao (2014) models the joint effect of SSDI benefits and Medicare eligibility on SSDI recipiency and labor supply, and Michaud and Wiczer (2017) use a model to measure the impact of health deterioration and concentration of health risks within certain occupations on SSDI claims. Kim and Rhee (2020) study the impact of temporarily restricting access to SSDI in a model where agents have heterogeneous human capital and Aizawa et al. (2020) derive an optimal disability policy in a model where firms strategically vary access to work flexibility in order to screen out disabled workers. Related empirical studies on SSDI include Autor and Duggan (2003) who document that the labor force participation rates of high school dropouts are responsive to the stringency and generosity of the SSDI program, and French and Song (2014) and Maestas et al. (2013) who show that the labor force participation rates of marginal SSDI applicants are sensitive to successful SSDI benefit receipt. ${ }^{2}$

Our paper is also related to the empirical literature that has found substantial evidence that negative health shocks reduce labor force participation and earnings. Blundell et al.

\footnotetext{
${ }^{2}$ See also Bound (1989) and Von Wachter et al. (2011).
} 
(2020) find that 15 percent of the decline in employment from age 50 to 70 is due to declines in health in the US and UK. Similar to us, they find the effect to be larger among less educated workers. Bound et al. (1999) show that deteriorating health is an important determinant of the labor force participation rates of older Americans using the Health and Retirement Study. Using HRS data, Smith $(1999,2004)$ find that the onset of serious health events (such as cancer and heart disease) has substantial negative effects on employment and earnings. ${ }^{3} \mathrm{We}$ contribute to this literature by using a dynamic panel approach to estimate casual impacts of frailty on prime-age workers' earnings, hours and wages in the PSID.

While health has been shown to have negative effects on income, empirical findings on the impact of income on health are less conclusive. For instance, Sullivan and Von Wachter (2009) find that job losses of male workers in Pennsylvania led to higher mortality rates and Adda et al. (2009) find higher mortality rates due to permanent income declines in the United Kingdom. However, Adda et al. (2009) find that the increases in mortality are primarily due to increases in risky health behavior. Similarly, Black et al. (2015) find that negative impacts of job displacement on the health of Norwegian workers are mostly due to increases in smoking behavior. Consistently, Black et al. (2015) find no equivalent health effect on the displaced workers' spouses. Also, Schaller and Stevens (2015) find that job loss in the United States leads to worse mental health but no change in chronic health conditions or health care utilization, and Eliason and Storrie (2009) find that job loss increases alcohol-related hospitalizations in Sweden but has no impact on hospitalizations for cardiovascular disease. ${ }^{4}$ In contrast, Gathmann et al. (2021) find evidence that job loss increases cardiovascular death of men in Finland in addition to increasing hospitalizations due to alcoholism and mental illness. However, this finding is in contrast to that of Junna et al. (2020) who show that mortality due to heart disease decreased for Finns unemployed due to workplace downsizing.

Several papers have also looked at the impact of lottery winnings or inheritances on health and found no casual effect. ${ }^{5}$ As Cutler et al. (2011) discuss in a survey of the literature on health and socioeconomic status, there is little evidence that income and wealth have substantial casual effects on adult health in developed countries including the United States. Education, on the other hand, is an important determinant of health dynamics at all ages. Cutler et al. (2011) argue that this is driven by the effect that education has on behavior as opposed to resources. ${ }^{6}$ Our findings on the absence of a causal impact from earnings to health are consistent with the findings in this literature. Given both the literature and our own findings, our quantitative analysis focuses on the effects going from health to earnings taking differences in health dynamics over the adult lifecycle by education as exogenous and assuming no feedback effects from earnings to health.

The remainder of the paper is organized as follows. In Section 2 we document empirical facts on the relationship between health status and earnings. These facts are used to guide the development of the model we present in Section 3. The calibration of the model is

\footnotetext{
${ }^{3}$ See also Au et al. (2005), García Gómez and López Nicolás (2006), García-Gómez et al. (2013), Lenhart (2019), Lundborg et al. (2015), Dobkin et al. (2018), Heinesen and Kolodziejczyk (2013), Jeon (2017), Pelkowski and Berger (2004) and Pohl et al. (2013).

${ }^{4}$ Keefe et al. (2002) reports similar findings for New Zealand and Browning et al. (2006) for Denmark.

${ }^{5}$ See Apouey and Clark (2015), Cesarini et al. (2016), Meer et al. (2003) and Raschke (2019).

${ }^{6}$ See Conti et al. (2010a,b); Heckman et al. (2018) among many others, for estimates of the effect of childhood education on health.
} 
outlined in Section 4. In Section 5 we assess the model's ability to replicate non-targeted moments. Section 6 reports the results of our quantitative exercises and Section 7 concludes.

\section{Empirical Facts on Health and Earnings}

We start by documenting some empirical facts on the relationship between health status and earnings that we use to guide the development of our structural model. However, first, we need to introduce and motivate our measure of health status: the frailty index. Our brief overview draws heavily on Hosseini et al. (forthcoming) which includes additional details on the properties of the index and provides an extensive comparison between it and other commonly-used measures of health.

As individuals age they develop an increasing number of health problems. Some of these conditions are rather mild (e.g., reduced vision) while others are serious (e.g., heart disease). However, as the number of conditions rises, the person's body becomes more frail and vulnerable to adverse outcomes. We refer to each of these conditions as a deficit. In their pioneering work, Mitnitski et al. (2001) and Mitnitski et al. (2002) demonstrated that the health status of an individual can be represented by an index variable, called the frailty index, which summarizes the individual's accumulated deficits. The index is constructed as the ratio of deficits a person has accumulated to the total number of deficits considered. ${ }^{7}$

We use three datasets to quantify the impact of health inequality on lifetime earnings inequality: PSID, HRS, and MEPS. To construct frailty indices for individuals in each dataset we use health deficit variables from three broad categories: restrictions and difficulties in Activities of Daily Living (ADLs) and Instrumental ADL (IADLs); mental and cognitive impairments; and medical diagnosis and measurements. Examples of deficits in the first category are difficulty eating, dressing, or walking across a room without assistance. Examples from the second category are cognitive and memory test scores from tests of abilities such as backwards counting and immediate word recall. Examples from the third category are having received a diagnoses of high blood pressure, diabetes, or obesity.

We construct our PSID sample using eight waves of the PSID covering the period 2002$2016 .{ }^{8}$ Our extended sample consists of household heads and spouses ages 25 to 94 . However, we restrict the sample to ages 25 to 64 for the empirical (dynamic panel) analysis below. Table 1 provides summary statistics on frailty for individuals in the dynamic panel sample. ${ }^{9}$ Notice that the cross-sectional distribution of frailty is right-skewed, and mean frailty increases with age and decreases with education. We use 27 deficit variables to construct the frailty index in PSID. Thus, incurring one additional deficit increases one's frailty index by $1 / 27$ or 3.7 percent. Wave-to-wave changes in frailty occur for 42 percent of the sample on average, 69 percent of which are increases.

\footnotetext{
${ }^{7}$ We show in Hosseini et al. (forthcoming) that the properties of the index are robust to alternative weighting schemes such as principal component weighting. Equal weighting works well because individuals with more severe conditions are likely to have more total deficits. For instance, consider two individuals with cancer. The one with a more serious case will likely also report limitations with ADLs and IADLs.

${ }^{8}$ Our sample starts in 2002 because the PSID did not collect enough information on individuals' medical conditions, ADLs or IADLs prior to the 2003 wave to construct frailty indices.

${ }^{9}$ See Section 1 of the Online Appendix for additional summary statistics and sample selection information.
} 
Table 1: Frailty Summary Statistics in PSID Dynamic Panel Sample

\begin{tabular}{cclc}
\hline $\begin{array}{c}\text { Mean } \\
\text { by age: }\end{array}$ & 0.11 & $\begin{array}{l}\text { Median } \\
\text { Standard Deviation }\end{array}$ & 0.07 \\
$25-34$ & 0.07 & & 0.11 \\
$35-44$ & 0.09 & Wave-to-wave: & \\
$45-54$ & 0.11 & $+\Delta$ Frailty & 0.29 \\
$55-64$ & 0.15 & $-\Delta$ Frailty & 0.13 \\
by education: & & & \\
Less than high school & 0.16 & Effect of 1 additional deficit & +0.037 \\
High school & 0.12 & & \\
College & 0.08 & & \\
\hline
\end{tabular}

We use the frailty index to measure health for our analysis because it has several attractive properties for studying individuals' life-cycle health dynamics and their implications. First, despite its simplicity, it is well documented in Gerontology that the index is highly predictive of health outcomes. ${ }^{10}$ Second, the frailty index measures health at a fine enough level that it can be treated as a continuous variable. This is a desirable feature for two reasons. One, it allows us to quantify the impact of marginal changes in frailty on economic outcomes as we do in our dynamic panel analysis. Two, as Table 1 shows, the distribution of frailty is significantly right-skewed meaning there is substantial variation in the extent of poor health among individuals in the unhealthy right-tail. As we will show below, the impacts of declines in health on earnings and labor supply are concentrated in this unhealthy tail of the distribution. Targeting this variation when calibrating our structural model is important for accurately quantifying the impact of health on lifetime earnings inequality but doing so requires having a sufficiently fine measure of health.

Figure 1 shows the raw correlations of frailty with earnings, participation, hours conditional on working, and wages by 5 -year age groups for individuals aged 25 to $74 .{ }^{11}$ The figure shows that frailty and earnings are negatively correlated at all ages. The negative correlation is $\mathrm{u}$-shaped over the life cycle with the magnitude peaking during the fifties. Notice that this negative correlation is due to a negative correlation between frailty and all three components of earnings (participation, hours, and wages). However, of the three, the correlation between frailty and participation is the largest and follows a similar life cycle pattern to that of earnings.

\footnotetext{
${ }^{10}$ For instance, Mitnitski et al. (2004) found that having a higher frailty index is associated with a higher likelihood of death or institutionalization. See also Searle et al. (2008); Rockwood and Mitnitski (2007), Rockwood et al. (2007), Mitnitski et al. (2001), Mitnitski et al. (2005), Kulminski et al. (2007a), Kulminski et al. (2007b), Goggins et al. (2005), and Woo et al. (2005).

${ }^{11}$ Earnings are annual labor earnings where labor earnings of non-workers are set to zero. Individuals are counted as participating in the labor force if they worked at least 260 hours during the year at a wage of at least $\$ 3$ per an hour. Annual hours worked are calculated as weekly hours times weeks worked. Wages are constructed by PSID using annual labor earnings and annual hours worked.
} 


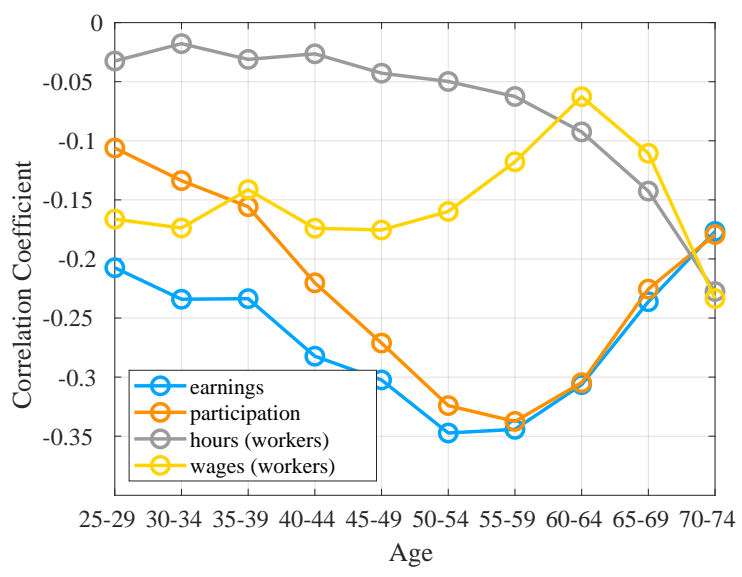

Figure 1: Raw correlations of earnings, participation, hours conditional on working and observed wages with frailty for 25 to 74 year-olds by five-year age groups. Data source: 2003-2017 PSID.

\subsection{The impact of health on earnings}

How much of the negative correlation between frailty and earnings or employment is driven by declines in health generating declines in earnings and how important are the various margins? To answer this question, we now use a dynamic panel approach to estimate the causal impacts of frailty on earnings, hours and wages. We estimate the following statistical model

$$
y_{i, t}=b_{i}+\gamma f_{i, t}+\alpha_{1} y_{i, t-1}+\alpha_{2} y_{i, t-2}+\delta \boldsymbol{Z}_{i, t}+\varepsilon_{i, t},
$$

in which $y_{i, t}$ is the logarithm of either earnings, hours, or wages for individual $i$ at time $t$. $f_{i, t}$ is frailty and $\boldsymbol{Z}_{i, t}$ is a vector of exogenous controls that includes marital status, marital status interacted with gender, number of kids, number of kids interacted with gender, year dummies, and a quadratic in age. ${ }^{12}$ Finally, $b_{i}$ is the individual fixed effect and $\varepsilon_{i, t}$ is a random error term with

$$
E\left[b_{i}\right]=E\left[\varepsilon_{i, t}\right]=E\left[b_{i} \varepsilon_{i, t}\right]=0 .
$$

Individuals vary in unobservable ways (such as innate ability) that could potentially be correlated with both their earning ability and frailty. This motivates the inclusion of a fixed effect in equation (1). ${ }^{13}$

We are interested in estimating the impact of frailty on earnings. However, earnings may also impact frailty. Declines in health may affect productivity and lead to lower wages (or loss of employment). Yet, lower income (or loss of employment) may negatively impact health through its impact on mental health, access to health insurance, or choice of medical

\footnotetext{
${ }^{12}$ We have also experimented with making marital status, marital status interacted with gender, number of kids, and number of kids interacted with gender endogenous and found that it does not have a significant impact on any of our results.

${ }^{13}$ The individual fixed effect controls for any non-time-varying heterogeneity across individuals including, for example, differences in gender and education. While we have done are best to include all relevant controls, we cannot completely rule out the possibility that we have omitted time-varying variables that are correlated with both frailty and are left-hand-side variables.
} 
care. Moreover, both earnings and frailty are highly persistent variables. In other words, we are concerned about simultaneity but also dynamic endogeneity: past earnings are correlated with current earnings but may also be correlated with both past and current frailty. This concern is the reason why we use a dynamic panel data approach. We need to include lagged values of earnings on the right-hand-side in equation (1).

It is well known that equation (1) cannot be consistently estimated using OLS or fixed effect estimators (see Nickell (1981) and Wooldridge (2010) for details). Therefore, to obtain a consistent and unbiased estimate of the effect of frailty on earnings we use a dynamic GMM panel estimator. This class of estimators was introduced by Holtz-Eakin et al. (1988) and Arellano and Bond (1991), and further developed by Blundell and Bond (1998) (and many others). ${ }^{14}$

The basic estimation procedure consists of two steps. The first step is to write equation (1) in first difference form:

$$
\Delta y_{i, t}=\gamma \Delta f_{i, t}+\alpha_{1} \Delta y_{i, t-1}+\alpha_{2} \Delta y_{i, t-2}+\delta \Delta \boldsymbol{Z}_{i . t}+\Delta \varepsilon_{i, t}
$$

which eliminates time-invariant unobserved heterogeneity. The second step is to use lagged values of the left-hand-side variable, frailty, and the endogenous controls in levels as 'internal' instruments and estimate equation (2) using GMM. As we argued above, lagged values of frailty and earnings are predictors of current levels of earnings and frailty. Therefore, they provide sources of variations for current values. However, for instruments to be valid, the past levels of earnings and frailty must be uncorrelated with $\varepsilon_{i, t}$. In other words, the following orthogonality or moment conditions must hold

$$
E\left(y_{i, t-s} \Delta \varepsilon_{i, t}\right)=E\left(f_{i, t-s+2} \Delta \varepsilon_{i, t}\right)=0, \quad \text { for } \forall s>3 .
$$

Using the moment conditions in equation (3) we can estimate equation (2) via GMM. However, there are still a few shortcomings. For example, differencing can reduce variation in explanatory variables and therefore reduce accuracy of estimates (see Beck et al. (2000)). Moreover, as Arellano and Bover (1995) point out, variables in levels may be weak instruments for first-differences. This is especially true for highly persistent variables. ${ }^{15}$ To mitigate these shortcomings, we follow Blundell and Bond (1998) and Blundell and Bond (2000) and improve the GMM estimator by jointly estimating the equation in levels and the equation in first-differences. Lagged first-differences are used to instrument levels. More precisely, we stack levels and first differences in the following equation

$$
\left[\begin{array}{c}
y_{i, t} \\
\Delta y_{i, t}
\end{array}\right]=\gamma\left[\begin{array}{c}
f_{i, t} \\
\Delta f_{i, t}
\end{array}\right]+\alpha_{1}\left[\begin{array}{c}
y_{i, t-1} \\
\Delta y_{i, t-1}
\end{array}\right]+\alpha_{2}\left[\begin{array}{c}
y_{i, t-2} \\
\Delta y_{i, t-2}
\end{array}\right]+\delta\left[\begin{array}{c}
\boldsymbol{Z}_{i . t} \\
\Delta \boldsymbol{Z}_{i . t}
\end{array}\right]+\varepsilon_{i, t},
$$

\footnotetext{
${ }^{14}$ Dynamic panel estimators are widely used. In a related example Michaud and Van Soest (2008) use them to study the casual relation between health and wealth using HRS data. They find strong evidence that health impacts wealth and no evidence of a casual effect of wealth on health. Examples include the effect of board structure on firm performance (Wintoki et al. (2012)), capital accumulation and firm investment (Whited (1991)), the sensitivity of firm investments to available internal funds (Bond and Meghir (1994)), economic growth convergence (Caselli et al. (1996)), estimation of a labor demand model (Blundell and Bond (1998)), the relation between financial intermediary development and economic growth (Beck et al. (2000)), and the diversification discount (Hoechle et al. (2012)), among many others.

${ }^{15}$ As an stark example, imagine a random walk process. In that case, past levels are uncorrelated with first differences.
} 
which we can estimate using the "system" GMM estimator. Note, however, that the estimation drops the fixed effect from the levels equation. As a result, for first differences to be valid instruments of the levels, the following additional orthogonality conditions must hold

$$
E\left(\Delta y_{i, t-s}\left(b_{i}+\varepsilon_{i, t}\right)\right)=E\left(\Delta f_{i, t-s+2}\left(b_{i}+\varepsilon_{i, t}\right)\right)=0, \quad \text { for } \forall s>3 .
$$

To summarize, we carry out GMM panel estimation using the orthogonality conditions (3) and (5). These conditions imply that we can use lagged levels of our endogenous regressors $\left(y_{i, t}\right.$ and $\left.f_{i, t}\right)$ as instruments for our differenced equations and lagged differences as instruments for the levels equations, respectively. Given the concerns about instrument proliferation and overfitting discussed in Roodman (2009) we do not use all the available lags as instruments. Instead, we use only the fourth and fifth lags for the regressions that include everyone in the sample. To obtain valid instruments for the regressions that are run only on workers requires us to go back further in lag length. Thus, for these regressions we use the fifth and sixth lags. In addition, in all regressions run, we restrict the coefficients on the lags to be the same at each time $t$ by collapsing the instrument matrix. ${ }^{16}$

Following the recommendations in the literature by Roodman (2009), Bond (2002) and others, we conduct several tests of our specification, approach, and instrument set. In the tables that follow, we report test statistics for two sets of tests. ${ }^{17}$ First, we report the results of the tests for first and second-order serial correlation in the residuals of the difference equation. By construction, the residuals of the first-differenced equation should possess firstorder serial correction. However, if the assumption of serial independence in the errors in the levels equation is correct, the first-differenced residuals should not exhibit significant $\operatorname{AR}(2)$ behavior. Thus, if we pass the test for second-order serial correlation, it means that we have included enough lags to control for the dynamic aspects of our empirical relationship. As a result, any historical value of earnings beyond those lags is a potentially valid instrument since it will be exogenous to current earning shocks.

The second set of tests statistics we report are tests of the validity of our instruments. The system is over-identified in that we have more instruments than we do endogenous regressors. We conduct a Hansen-Sargan test and report the Hansen J-statistic. The Hansen J-statistic is distributed $\chi^{2}$ under the null hypothesis that there is no correlation between the error terms and the instruments. Finally, we report the test statistic for the difference-in-Hansen test that our lagged first-difference instruments are uncorrelated with the fixed effects. This must hold for lagged first-differences to be valid instruments of the endogenous variables in the levels equation since the fixed effect is still in the error term. ${ }^{18}$

We now present the results from our dynamic panel estimation. We report two sets of estimation results that highlight the differences in the effect of changes in frailty on the intensive versus the extensive margin of labor supply. The first set shows the results from

\footnotetext{
${ }^{16}$ This increases the power of the Hansen-Sargan test for over-identification.

${ }^{17}$ In Section 2 of the Online Appendix we show the results of additional tests and robustness checks including robustness checks to the number of instruments used, results from difference-in-Hansen tests on subsets of instruments in the levels equation, results of instrument power tests, and a comparison of our dynamic panel GMM estimates to both estimates obtained using an OLS estimator and a within groups (FE) estimator.

${ }^{18}$ There can still be correlation between the levels and the unobserved effects but this correlation must be constant over time.
} 
estimating equation (1) for everyone in our PSID sample, regardless of their labor force participation status. ${ }^{19}$ The second set reports results only for those who are working in all periods we observe them. To aid in the interpretation of their magnitude, we report all the estimated frailty effects (and their standard errors) as the impact of the accumulation of one additional deficit. To achieve this, we rescale all the coefficients on terms involving frailty by $1 / 27 .{ }^{20}$ For instance, the third row of column (1) in Table 2 reports $\gamma / 27$.

Table 2 reports the results from our system GMM estimation of equation (1) where the left-hand-side variable is log earnings. Columns (1) through (4) show the regression results for the entire sample. Columns (5) through (8) show results only for workers. Notice that the p-values from the $\mathrm{AR}(2)$, Hansen, and difference-in-Hansen tests are all above 5 percent. Thus, we cannot reject the nulls of no second-order serial correlation in the error terms and instrument validity.

As column (1) of Table 2 indicates, frailty has a large and statistically significant effect on earnings. Accumulating one more deficit reduces earnings, on average, by 20 percent. However, as column (5) shows, the effect of accumulating one additional deficit is much smaller when conditioning on those who continue to work. For workers, the overall effect is a 4 percent decline and is borderline significant. These findings suggest that, consistent with the magnitudes of the raw correlations in Figure 1, the effects of frailty on earnings are due primarily to the extensive margin (of unhealthy workers leaving employment), rather than the intensive margin (of unhealthy workers working fewer hours or receiving lower wages). ${ }^{21}$

Columns (2) and (6) of Table 2 show how the effects of frailty on earnings differ by education groups: high school dropouts (HSD), high school graduates (HS), and college graduates (CL). Looking at column (2), frailty has a large and strongly significant effect on the earnings of high school dropouts and those with no more than a high school degree. However, the effect is smaller and less significant for college graduates. One additional deficit reduces the earnings of high school dropouts, high school graduates, and college graduates by 23, 21, and 9 percent, respectively. Among workers, the effects by education group are considerably smaller and the levels of significance are lower. For instance, accumulating one more deficit reduces the earnings of high-school dropout workers by 7 percent and the earnings of high-school graduates by 5 percent.

Columns (3) and (7) of Table 2 show results by health status. Column (3) shows that frailty has a significant and large effect on the earnings of individuals with bad health. Here, individuals with bad health are those with a value of frailty above the 75 th percentile of the overall frailty distribution. For these individuals one more deficit leads to a 19 percent drop in earnings. The effect for individuals with good health (those with a value of frailty at or below the 75 th percentile) is small and insignificant. Once we restrict the sample to workers, the coefficient on frailty interacted with bad health becomes substantially smaller and less significant. These results show that the negative effects of frailty on earnings are primarily due to exit from the labor force in response to additional health declines by individuals who are already in poor health.

\footnotetext{
${ }^{19}$ To take logarithms, we shift all observations of annual earnings up by $\$ 1.00$.

${ }^{20}$ Recall that in our PSID sample we have a total of 27 potential deficits so accumulating one more deficit is equivalent to an increase in frailty by $\frac{1}{27}$.

${ }^{21}$ Since exit from the labor force due to bad health is likely often permanent, we focus our discussion on the estimated short-run effects of frailty on earnings and not longer-run effects due to earnings persistence.
} 
Table 2: Effect of Frailty on Earnings

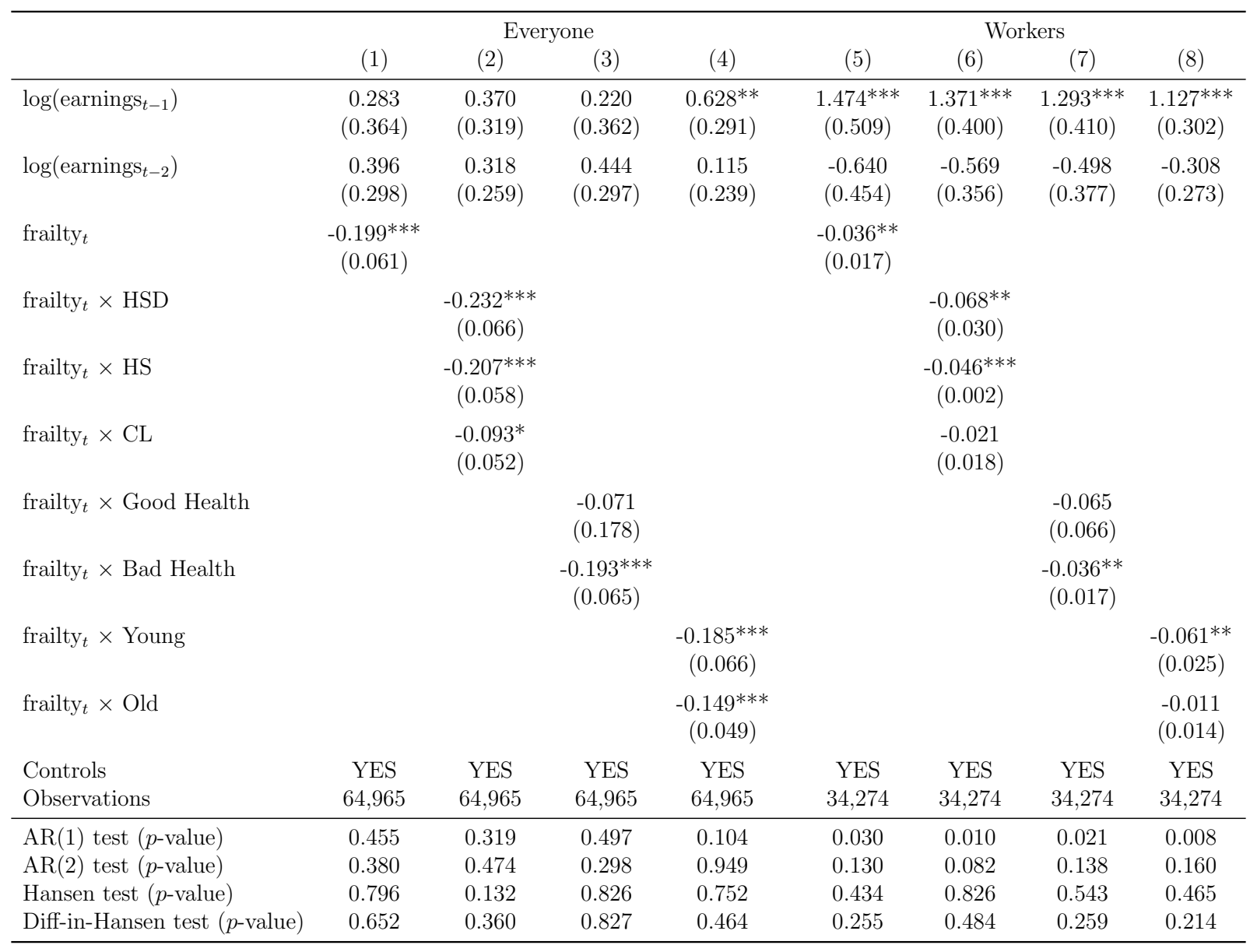

Notes: Columns (1)-(4) show regression results for the entire sample. Columns (5)-(8) show results conditional on continued employment. Frailty effects are reported as the effect of one additional deficit. Controls included are marital status, marital status interacted with gender, number of kids, number of kids interacted with gender, year dummies, and a quadratic in age. 'HSD' is high school dropout, 'HS' is high school graduate, and 'CL' is college graduate. 'Good/Bad Health' is frailty below/above the 75 th percentile. 'Young/Old' are individuals younger/older than 45 years of age. Standard errors are in parenthesis. ${ }^{*} p<0.1 ; * *<0.05 ;{ }^{* * *} p<0.01$.

Finally, columns (4) and (8) of Table 2 show the effects by age groups. Somewhat surprisingly, the effects of frailty on earnings are slightly smaller for those older than 45 than those younger than 45 . One additional deficit reduces earnings of the young by 18 percent and earnings of the old by 15 . In addition, once the sample is restricted to only those who continue to stay employed, the effect is only significant for younger workers. These estimates reveal that the effect of health on earnings for older workers operates primarily through the extensive margin. In contrast, there are potential effects operating through the intensive margin for younger workers. This suggests that, relative to older workers, younger workers may be more willing to continue working despite incurring reductions in labor earnings due to poor health.

The results in Table 2 tell us that frailty has a large and significant effect on the earnings of low educated individuals and those with bad health. They also indicate that the effect is mainly along the extensive margin. The impact on earnings of workers is either not 
significant or is relatively small. However, these results do not tell us whether the impacts on workers come from hours or wages, or both. To better understand how frailty affects hours and wages of workers, we repeat the same regressions but replace the independent variable with hours and/or wage. The results of these regressions are reported in Table 3.

The left panel in Table 3 (Panel A) shows the estimated effects of frailty on hours worked. The results in columns (1) to (4) show that, for the entire sample, the impact of accumulating one additional deficit on hours is very similar to the impact on earnings. Overall, accumulating one more deficit cause a 14 percent drop in hours. As with earnings, high school dropouts and those in bad health experience the largest declines in hours. College-educated and those in good health have the smallest impact.

Columns (5) through (8) of the table show the effect of frailty on hours for workers only. Note that we do not find any evidence of a significant effect either overall or in any of the subgroups we consider. This indicates that the impact of frailty on hours worked is almost entirely through exit from employment (as opposed to adjustment of working hours). In other words, if an adverse health event does not drive a worker out of employment, there will be no adjustment in hours worked, even among the high school dropouts (who experience the largest decline in earnings while working).

The right panel in Table 3 (Panel B) shows regression results for the effect of frailty on wages of workers. On average, one more deficit reduces wages of workers by 2 percent. The effect is negative for all three education groups but decreases with education and is only significant for less educated workers (those without a college degree). Of all subgroups we consider, the effect is largest for the high school dropout group. One additional deficit reduces their hourly wages by 7 percent. Notice that the effects on wages are very similar in magnitude to the effects on earnings of workers reported in Table 2.

\subsection{The impact of earnings on health}

The empirical analysis above focuses on estimating the causal effect of frailty on earnings, hours, and wages. However, it is also possible that earnings affects frailty. To examine this proposition we estimate the following regression

$$
f_{i, t}=b_{i}+\gamma y_{i, t}+\alpha_{1} f_{i, t-1}+\alpha_{2} f_{i, t-2}+\beta \boldsymbol{Z}_{i, t}+\varepsilon_{i, t},
$$

using the system GMM estimation procedure. Here, $f_{i, t}$ is the level of frailty of individual $i$ at date $t$ and $y_{i, t}$ is their date $t \log$ earnings. The set of controls $\boldsymbol{Z}_{i, t}$ is the same as in those in Section 2.1 and we run the same set of regressions as we did with log earnings on the left-hand-side. In particular, we look at the effect of log earnings on frailty overall and by education, health, and age. To get valid instruments for these regressions, we must go back further in lag length then we did for the regressions in Section 2. We also need to include more instruments. We use the sixth through eighth lags of frailty and log earnings as instruments.

The results are presented in Table 4. Notice that we find no evidence that earnings affects frailty. In all cases, the effects of log earnings on frailty are small and in only one regression do we see significance at the 10 percent level. Note also that, in all specifications, the diagnostic tests are passed. In other words, the error terms are not second order autoregressive and 


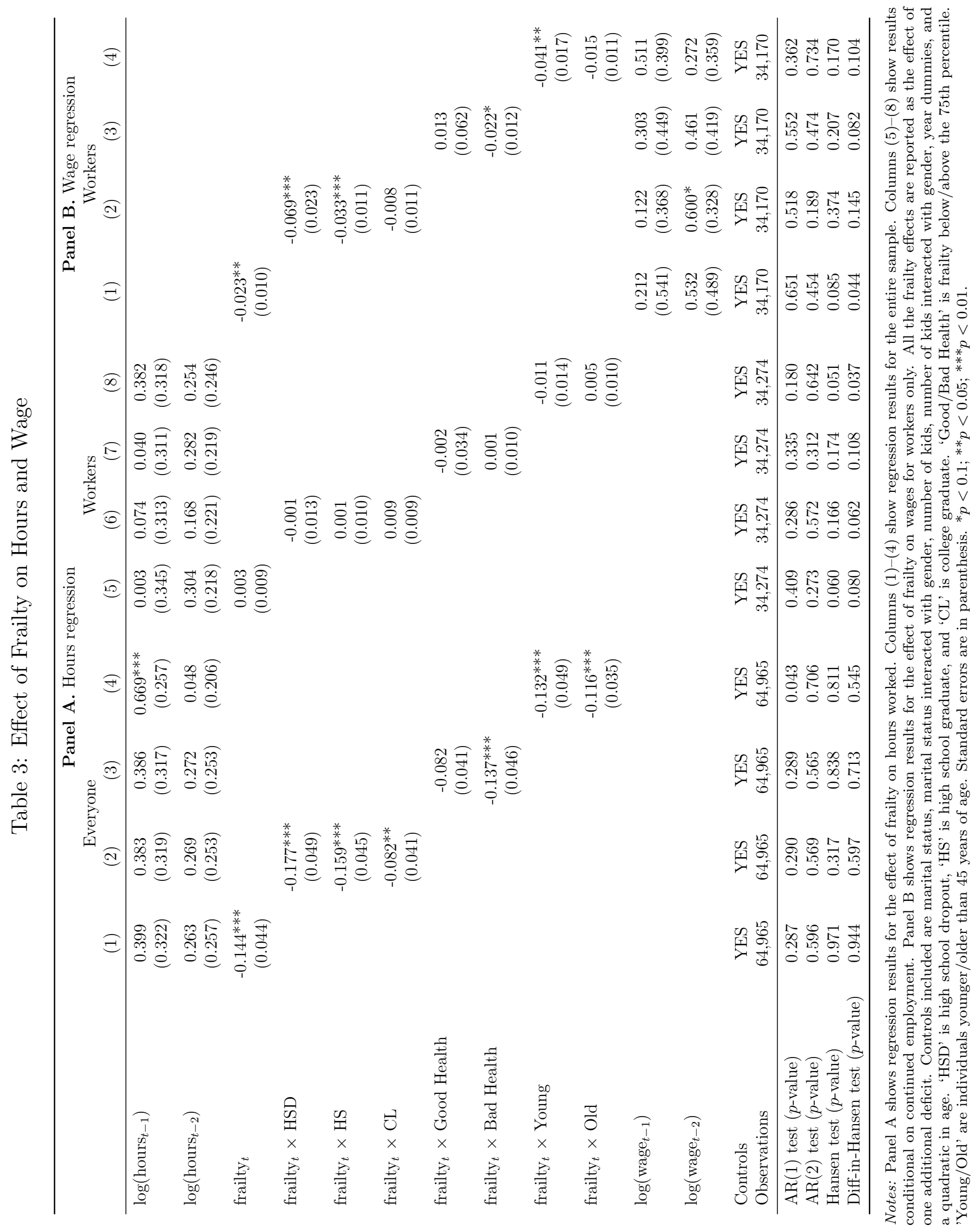


Table 4: Effect of Earnings on Frailty

\begin{tabular}{|c|c|c|c|c|c|c|c|c|}
\hline & \multicolumn{4}{|c|}{ Everyone } & \multicolumn{4}{|c|}{ Workers } \\
\hline & $(1)$ & $(2)$ & $(3)$ & (4) & $(5)$ & $(6)$ & $(7)$ & $(8)$ \\
\hline frailty $_{t-1}$ & $\begin{array}{c}0.445 \\
(0.463)\end{array}$ & $\begin{array}{c}0.334 \\
(0.435)\end{array}$ & $\begin{array}{c}-0.152 \\
(0.528)\end{array}$ & $\begin{array}{c}-0.456 \\
(0.400)\end{array}$ & $\begin{array}{c}-0.182 \\
(0.566)\end{array}$ & $\begin{array}{c}0.712^{*} \\
(0.416)\end{array}$ & $\begin{array}{c}0.302 \\
(0.737)\end{array}$ & $\begin{array}{c}-0.190 \\
(0.498)\end{array}$ \\
\hline frailty $_{t-2}$ & $\begin{array}{c}0.602 \\
(0.447)\end{array}$ & $\begin{array}{c}0.661 \\
(0.443)\end{array}$ & $\begin{array}{c}1.124^{* *} \\
(0.495)\end{array}$ & $\begin{array}{c}1.446^{* * *} \\
(0.404)\end{array}$ & $\begin{array}{c}1.316^{* *} \\
(0.596)\end{array}$ & $\begin{array}{c}0.405 \\
(0.451)\end{array}$ & $\begin{array}{c}0.820 \\
(0.741)\end{array}$ & $\begin{array}{c}1.321^{* *} \\
(0.529)\end{array}$ \\
\hline $\log \left(\right.$ earnings $\left._{t}\right)$ & $\begin{array}{c}0.004^{*} \\
(0.002)\end{array}$ & & & & $\begin{array}{c}-0.004 \\
(0.007)\end{array}$ & & & \\
\hline $\log \left(\right.$ earnings $\left._{t}\right) \times \mathrm{HSD}$ & & $\begin{array}{c}0.003 \\
(0.002)\end{array}$ & & & & $\begin{array}{c}0.001 \\
(0.002)\end{array}$ & & \\
\hline $\log \left(\right.$ earnings $\left._{t}\right) \times \mathrm{HS}$ & & $\begin{array}{c}-0.008 \\
(0.039)\end{array}$ & & & & $\begin{array}{l}-0.019 \\
(0.073)\end{array}$ & & \\
\hline $\log \left(\right.$ earnings $\left._{t}\right) \times \mathrm{CL}$ & & $\begin{array}{c}0.000 \\
(0.001)\end{array}$ & & & & $\begin{array}{l}-0.000 \\
(0.001)\end{array}$ & & \\
\hline $\log \left(\right.$ earnings $\left._{t}\right) \times$ Good Health & & & $\begin{array}{c}0.000 \\
(0.003)\end{array}$ & & & & $\begin{array}{c}0.000 \\
(0.008)\end{array}$ & \\
\hline $\log \left(\right.$ earnings $\left.s_{t}\right) \times$ Bad Health & & & $\begin{array}{c}0.002 \\
(0.002)\end{array}$ & & & & $\begin{array}{c}0.000 \\
(0.008)\end{array}$ & \\
\hline $\log \left(\right.$ earnings $\left._{t}\right) \times$ Young & & & & $\begin{array}{c}-0.000 \\
(0.001)\end{array}$ & & & & $\begin{array}{c}-0.004 \\
(0.007)\end{array}$ \\
\hline $\log \left(\right.$ earnings $\left._{t}\right) \times$ Old & & & & $\begin{array}{l}-0.000 \\
(0.002)\end{array}$ & & & & $\begin{array}{l}-0.003 \\
(0.007)\end{array}$ \\
\hline Controls & YES & YES & YES & YES & YES & YES & YES & YES \\
\hline Observations & 50,844 & 50,844 & 50,844 & 50,844 & 27,444 & 27,444 & 27,444 & 27,444 \\
\hline $\mathrm{AR}(1)$ test ( $p$-value) & 0.531 & 0.573 & 0.501 & 0.001 & 0.260 & 0.388 & 0.763 & 0.188 \\
\hline $\operatorname{AR}(2)$ test ( $p$-value $)$ & 0.333 & 0.260 & 0.061 & 0.002 & 0.060 & 0.570 & 0.380 & 0.032 \\
\hline Hansen test ( $p$-value) & 0.269 & 0.842 & 0.621 & 0.129 & 0.440 & 0.430 & 0.747 & 0.848 \\
\hline Diff-in-Hansen test ( $p$-value) & 0.450 & 0.852 & 0.894 & 0.132 & 0.656 & 0.225 & 0.805 & 0.818 \\
\hline Diff-in-Hansen test ( $p$-value), Y-lag set & . & 0.990 & 0.723 & 0.223 & . & 0.245 & 0.814 & 0.788 \\
\hline
\end{tabular}

Notes: Columns (1)-(4) show regression results for the entire sample. Columns (5)-(8) show results conditional on continued employment. Controls included are marital status, marital status interacted with gender, number of kids, number of kids interacted with gender, year dummies, and a quadratic in age. 'HSD' is high school dropout, 'HS' is high school graduate, and ' $\mathrm{CL}$ ' is college graduate. 'Good/Bad Health' is frailty below/above the 75th percentile. 'Young/Old' are individuals younger/older than 45 years of age. Standard errors are in parenthesis. ${ }^{*} p<0.1 ;{ }^{* *} p<0.05 ;{ }^{* * *} p<0.01$.

the Hansen-Sargan tests indicate that the null hypothesis of valid instruments cannot be rejected. These findings are consistent with the empirical literature discussed in Section 1.1 that finds little or no effect of earnings, wealth, or labor supply on adult health. Thus, in the structural model that follows we assume frailty is exogenous. However, given the large differences in health by education we allow the dynamics of frailty over the lifecycle to be education specific.

\subsection{Summary of empirical findings}

To summarize, our empirical analysis yields the following five findings. One, increases in frailty significantly reduce earnings and hours worked. Two, this effect is mainly due to the extensive margin. Three, the effect is concentrated among less educated individuals and those already in poor health. Four, increases in frailty also reduce wages of workers without 
a college degree. Five, there is no evidence of significant effects of changes in earnings on health.

Consistent with these findings, Figure 2 shows the variation in labor force participation rates by age and frailty percentile groups in our PSID sample. For all age groups, there is little variation in labor force participation by frailty when frailty is below the 70th percentile. At the same time, individuals with frailty in the top 5 percent have significantly lower participation rates. Consistent with Figure 1, the overall dispersion in labor force participation rates is most pronounced for individuals in their fifties. In particular, at ages 55-59, only 20 percent of individuals in the top 5 percentiles of frailty are employed compared with more than 90 percent of those in the 0 to 70 th percentiles.

The fact that the impact of frailty on earnings works primarily through the participation margin, suggests that the DI program may be an important factor driving this effect. Highly frail individuals have an increased likelihood of obtaining DI benefits and DI application and recipiency generates strong work disincentives. Individuals who apply for DI must be unemployed or have very low earnings, lower than the substantial gainful activity (SGA) threshold, for at least 5 months before benefit receipt can occur. ${ }^{22}$ Once on DI, recipients whose earnings rise above the SGA threshold face the risk of losing benefits. As a result, most DI beneficiaries do not work. ${ }^{23}$ The right panel of Figure 2 shows the fraction of individuals who are on SSDI or SSI for each 5 year age group from age 25 to 64 and the same frailty percentile groups as in Figure 2. ${ }^{24}$ The pattern of DI recipiency by frailty and age is very similar to that by labor force participation. There is little variation by frailty until frailty is above the 70th percentile of the distribution and then the variation is substantial. Eighty percent of 55-59 year olds in the top 5 percent of the frailty distribution are on DI while the fraction is nearly zero for those with frailty below the 70th.

\section{The Model}

Given the findings in Section 2, we build a structural model that features individuals with risky and heterogeneous frailty profiles. We focus the model on the participation margin: individuals chose to participate in the labor market or exit and apply for DI. Given that we did not find any statistically significant effects of frailty on hours conditional on working, we do not model the intensive margin of labor supply. However, we do allow for poor health to impact individuals' labor productivity and for this effect to be concentrated in individuals with less education. Fraily profiles are exogenous in the model since we do not find a statistically significant feedback effect from earnings to health.

\footnotetext{
${ }^{22}$ For example, in 2019 the SGA threshold was $\$ 1,220$ per month.

${ }^{23}$ Maestas et al. (2013) document that in 2005 only 13 percent of SSDI applicants who started receiving benefits three years ago were employed.

${ }^{24}$ The figure is constructed using MEPS data. MEPS contains information on SSI beneficiary status but not SSDI. However, it does include data on whether an individual receives Medicare benefits. SSDI beneficiaries are the only group younger than 65 years of age who qualify for Medicare (after being on SSDI for two years). We compute the fraction in each frailty and age group who receive SSI or Medicare benefits in MEPS. We then adjust the fractions by the Social Security Administration population data on SSDI and SSI recipient by age so that the numbers are consistent on aggregate.
} 


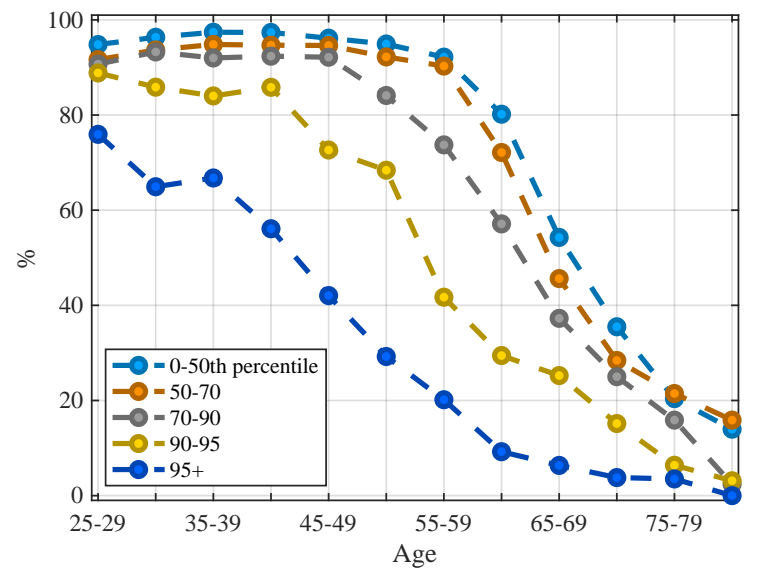

(a) Labor force participation rates

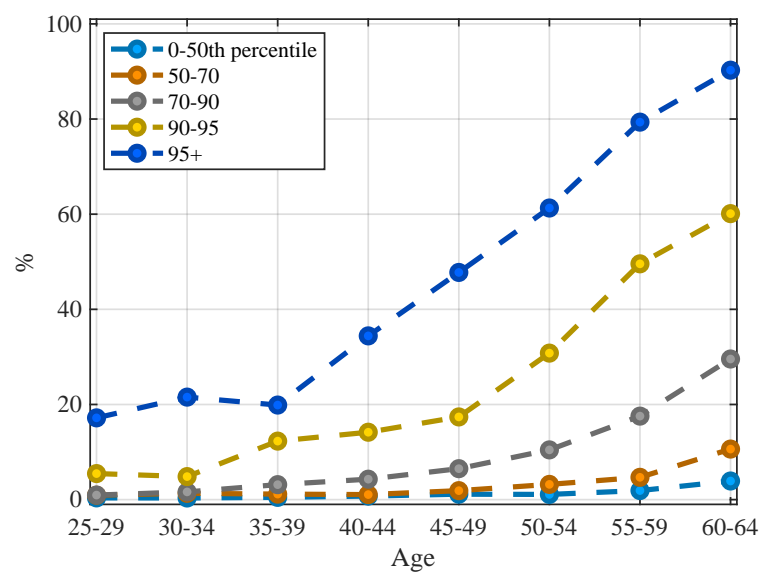

(b) DI recipiency rates

Figure 2: Labor force participation rates (left) and DI recipiency rates (right) by frailty percentiles groups and age. Source: Authors' calculations using PSID data (left) and MEPS and Social Security Administration data (right).

\subsection{Demographics}

Time is discrete and one period is one year. The economy is populated by a continuum of individuals in $J$ overlapping generations. The population grows at rate $\nu$. Each period an age $j=1$ cohort is born and lives up to the maximum age $j=J$. Individuals' health status is summarized by their frailty index, $f$, which evolves stochastically as we describe below. Frailty affects labor productivity, disutility from working, out-of-pocket medical expenditures and mortality risk. It also affects the chance of becoming a DI beneficiary. At each age $j$, the probability of surviving one more year depends on frailty, $f$, and education level, $s$, and is denoted by $p(j, f, s)$. Individuals are ex ante heterogeneous with respect to their education level, and they face a labor productivity process that is uncertain due to its dependence on both their frailty and direct labor productivity shocks.

Before retirement, each individual is either employed, non-employed or enrolled in DI. An employed individual works a fixed (exogenously given) fraction of time and earns wage $w \cdot \eta(j, f, s, \epsilon)$ which is the product of two terms. The first term is the wage per efficiency unit of labor services, $w$. The second term is the efficiency unit of labor services per hour worked, $\eta(j, f, s, \epsilon)$. This depends on the worker's age $j$, frailty $f$, education $s$, and a stochastic component $\epsilon$. The stochastic component, $\epsilon$, consists of both a fixed effect and a persistent shock. $^{25}$ It evolves according to transition probability $\pi^{e}\left(\epsilon^{\prime} \mid j, \epsilon, s\right)$, which depends on age $j$ and education $s$. Employed workers may choose to quit and become non-employed. They can also become exogenously separated from their job with probability $\sigma$.

A non-employed individual can apply for DI or choose to go back to work immediately. ${ }^{26}$

${ }^{25}$ We do not include a transitory shock directly in the productivity process. However, the fact that individuals in the model face a positive probability of an exogenous job separation means that there is a transitory component to earnings risk.

${ }^{26}$ In our model, individuals who spend more than one year out of the labor force for health reasons are trying to get on DI. This is consistent with the findings in Gifford (2017) that temporary work leaves due to 
If he applies for DI, he is awarded benefits with probability $\theta\left(f, n_{a}\right)$ in the next period. Here, $n_{a}$ indicates the number of times he has applied for DI consecutively in the past. Individuals who are awarded DI benefits remain on DI until age $R<J$. After that, they transition to receiving social security retirement benefits. Those who choose to go back to work, have to pay a penalty $\chi(w \eta)$, which is a function of their current wage and can be understood of as the cost of job search. ${ }^{27}$

Those who are older than retirement age $R$ receive social security retirement benefits but can choose to work or retire. Once an individual chooses to retire he remains retired until death. Both social security retirement and social security disability benefits, including SSI payments, are given by $S S(\bar{e})$, which is a function of the beneficiary's earning history, $\bar{e}^{28}$

Everyone has access to a risk-free asset $a$ that pays return $r$. There are no other financial assets in the economy.

\subsection{Frailty and medical expenditures}

An individual's frailty is given by $f \equiv \psi\left(j, s, \epsilon_{f}\right)$. It depends on his age, $j$, education level, $s$, and a stochastic component, $\epsilon_{f}$. The stochastic component consists of a fixed effect, a persistent shock, and a transitory shock. An individual whose stochastic component of frailty this period is given by $\epsilon_{f}$ will have value $\epsilon_{f}^{\prime}$ next period with probability $\pi^{f}\left(\epsilon_{f}^{\prime} \mid j, \epsilon_{f}, s\right)$.

Out-of-pocket medical expenditures are a deterministic function of age, education, frailty, and employment status. An individual of age $j$ and education $s$ who has frailty $f$ incurs out-of-pocket medical expenditures $m^{i}(j, f, s)$ where $i=E, N, D, R$ depending on whether he is employed $(E)$, non-employed $(N)$, a DI beneficiary $(D)$ or retired $(R) .{ }^{29}$

\subsection{Government}

The government runs a social security retirement and disability program which provides benefit $S S(\bar{e})$ to individuals $R$ and older and individuals under age $R$ who successfully enroll in DI. These benefits depend on individuals past earnings and include both social security benefits and SSI. The government also runs a means-tested transfer program that guarantees individuals a minimum level of consumption of $\underline{c}$. Transfers, $\operatorname{Tr}(a, y)$, depend on individuals assets, $a$, and after-tax income net of medical expenditures and job search costs, $y$. The transfer is zero if $a+y \geq \underline{c}$. Otherwise, it is just enough to provide consumption level $\underline{c}$. The government also has exogenous expenditures $G$. It raises revenue by levying a nonlinear tax on labor income, $T(w \eta)$, and a proportional tax on capital income, $\tau_{K}$ (paid by the firm). Due to the absence of annuity markets, individuals may die with positive assets. We assume that the government taxes these accidental bequests at a rate of 100 percent.

disability tend to be much shorter than one year, averaging 115 days with a median of 47 days. These types of leaves are captured in the model through the impact of health on labor productivity.

${ }^{27}$ We only include the monetary/income costs of short-term joblessness and abstract from the details of unemployment and job search. This modeling choice is motivated by the fact that the average duration of unemployment in the US is 15-20 weeks which is shorter than a period in our model.

${ }^{28}$ The U.S. Social Security administration uses the same benefit formula to calculate both retirement and disability benefits, and the SSI benefit formula does not depend on retirement status.

${ }^{29}$ All workers who are older than age $R$ are Medicare beneficiaries and face the same process for out-ofpocket medical expenditures as retirees. 


\subsection{Individual decision problems}

To economize on notation we denote a subset of the state space as $x \equiv(j, a, f, s, \epsilon, \bar{e}) .{ }^{30}$ Let $V^{E}\left(x, i_{s}\right)$ be the value function of an employed individual, $V^{N}\left(x, n_{a}\right)$ be the value function of a non-employed individual, $V^{D}\left(x, n_{d}\right)$ be the value function of a DI beneficiary, and $V^{R}(x)$ be the value function of a retiree. The variable $i_{s}$ is an indicator that an employed worker is returning from an exogenous separation or non-employment spell. Variable $n_{a}$ tracks the number of periods an individual has been in non-employment consecutively in the past. Recall that workers can always go back to employment immediately. If they stay in non-employment, it is because they are applying for DI benefits. Therefore, $n_{a}$ is also equal to the number of times an individual has applied for DI consecutively in the past. Variable $n_{d}$ represents the number of periods an individual has been on DI. This variable is used to determine his eligibility for Medicare benefits. Period utility, $u(c, l, f)$, depends on consumption, $c$, labor force status $l \in\{0,1\}$ where 1 denotes working and 0 denotes not working and frailty, $f$. Individuals discount the future at rate $\beta$. We now describe the problems facing each type of individual.

The employed worker's problem: employed workers face the risk of exogenously separating from their employer with probability $\sigma$ at the beginning of the next period. If separated, they can choose to go back to work immediately. If they survive the separation shock, they can choose to quit the job voluntarily. When $j<R-1$, their utility-maximization problem can be specified as follows,

$$
\begin{aligned}
V^{E}\left(x, i_{s}\right) & =\max _{c, a^{\prime} \geq 0} u(c, 1, f) \\
& +\sigma \beta p(j, f, s) E\left[\max \left\{V^{E}\left(x^{\prime}, 1\right), V^{N}\left(x^{\prime}, 0\right)\right\}\right] \\
& +(1-\sigma) \beta p(j, f, s) E\left[\max \left\{V^{E}\left(x^{\prime}, 0\right), V^{N}\left(x^{\prime}, 0\right)\right\}\right]
\end{aligned}
$$

subject to

$$
\frac{a^{\prime}}{1+r}+c+m^{E}(j, f, s)=a+w \eta(x)-T(w \eta(x))-\chi(w \eta(x)) i_{s}+\operatorname{Tr}\left(x, i_{s}\right),
$$

and $\bar{e}^{\prime}=[(j-1) \bar{e}+w \eta(x)] / j$. When workers return from a separation or non-employment $\left(i_{s}=1\right)$, they have to pay a penalty $\chi(w \eta(x))$, which is a function of their hourly wages. Employment decisions of these workers at the beginning of the period are denoted by $I_{E}\left(x, i_{s}\right)$.

After reaching age $R$, employed workers can only choose between working and retirement (not working). However, they are eligible to claim social security retirement benefits regardless of whether they work or not. ${ }^{31}$ They are also eligible for Medicare, which affects their out-of-pocket medical expenditures. Therefore, employed workers of age $j \geq R-1$ face the following optimization problem,

\footnotetext{
${ }^{30}$ To avoid clutter, we use $x$ as the argument of functions with the understanding that not all functions depend on all elements of $x$.

${ }^{31}$ We make this assumption for simplicity. Aside from the tax implications, which Jones and Li (2018) find to have a relatively small effect on the labor supply of older workers, there is no cost of working past full retirement age while also claiming benefits.
} 


$$
\begin{aligned}
V^{E}\left(x, i_{s}\right) & =\max _{c, a^{\prime} \geq 0} u(c, 1, f) \\
& +\sigma \beta p(j, f, s) E\left[\max \left\{V^{E}\left(x^{\prime}, 1\right), V^{R}\left(x^{\prime}\right)\right\}\right] \\
& +(1-\sigma) \beta p(j, f, s) E\left[\max \left\{V^{E}\left(x^{\prime}, 0\right), V^{R}\left(x^{\prime}\right)\right\}\right]
\end{aligned}
$$

subject to

$$
\begin{aligned}
\frac{a^{\prime}}{1+r}+c+m^{R}(j, f, s) & =a+w \eta(x)+S S(\bar{e})-T(w \eta(x))-\chi(w \eta(x)) i_{s}+\operatorname{Tr}\left(x, i_{s}\right), \\
\bar{e}^{\prime} & =\bar{e} .
\end{aligned}
$$

The non-employed's problem: non-employed individuals apply for DI. They qualify for benefits with probability $\theta\left(f, n_{a}\right)$. If awarded, they start receiving them in the following period and will remain on DI until they reach retirement age $R .{ }^{32}$ At that time, they move to social security. If not awarded, they can go back to work immediately or remain nonemployed and apply again. When $j<R-1$, the non-employed individual's problem can be specified as follows,

$$
\begin{aligned}
V^{N}\left(x, n_{a}\right) & =\max _{c, a^{\prime} \geq 0} u(c, 0, f) \\
& +\theta\left(f, n_{a}\right) \beta p(j, f, s) E\left[V^{D}\left(x^{\prime}, 0\right)\right] \\
& +\left(1-\theta\left(f, n_{a}\right)\right) \beta p(j, f, s) E\left[\max \left\{V^{E}\left(x^{\prime}, 1\right), V^{N}\left(x^{\prime}, n_{a}+1\right)\right\}\right]
\end{aligned}
$$

subject to

$$
\frac{a^{\prime}}{1+r}+c+m^{N}(j, f, s)=a+\operatorname{Tr}\left(x, n_{a}\right) .
$$

Employment decisions of these workers are denoted by $I_{N}\left(x, n_{a}\right)$.

When $j=R-1$, non-employed individuals cannot apply for DI anymore as they will reach the retirement age in the next period. The problem facing them becomes,

$$
V^{N}\left(x, n_{a}\right)=\max _{c, a^{\prime} \geq 0} u(c, 0, f)+\beta p(j, f, s) E\left[\max \left\{V^{E}\left(x^{\prime}, 1\right), V^{R}\left(x^{\prime}\right)\right\}\right]
$$

subject to $(12)$.

The DI beneficiary's problem: DI recipients only make consumption and saving decisions. It is important to note that DI recipients can also get access to Medicare benefits after enrolled in DI for two years. In the model, this eligibility is determined by the state variable $n_{d}$, which represents the number of periods the individual has been on DI. When $j<R-1$, DI recipients face the following problem,

\footnotetext{
${ }^{32}$ We do not model exits from DI due to reasons other than transition to old-age social security or death because they are extremely rare. According to the Social Security Administration, in 2018, the fraction who exited due to the next two most common reasons were 0.6 percent (who exited because they earned more than the maximum allowed level) and 0.5 percent (who exited because they were deemed medically able to work during a medical review).
} 


$$
V^{D}\left(x, n_{d}\right)=\max _{c, a^{\prime} \geq 0} u(c, 0, f)+\beta p(j, f, s) E\left[V^{D}\left(x^{\prime}, n_{d}+1\right)\right]
$$

subject to

$$
\frac{a^{\prime}}{1+r}+c+m^{D}\left(j, f, s, n_{d}\right)=a+S S(\bar{e})+\operatorname{Tr}\left(x, n_{d}\right) .
$$

When DI beneficiaries reach retirement age $R$, they automatically move from disability insurance to social security. Therefore, for $j=R-1$,

$$
V^{D}\left(x, n_{d}\right)=\max _{c, a^{\prime} \geq 0} u(c, 0, f)+\beta p(j, f, s) E\left[V^{R}\left(x^{\prime}\right)\right]
$$

subject to $(15)$.

The retiree's problem: retirees remain retired until they die. They receive social security benefits and only make consumption and saving decisions. Their problem is given by

$$
V^{R}(x)=\max _{c, a^{\prime} \geq 0} u(c, 0, f)+\beta p(j, f, s) E\left[V^{R}\left(x^{\prime}\right)\right]
$$

subject to

$$
\frac{a^{\prime}}{1+r}+c+m^{R}(j, f, s)=a+S S(\bar{e})+\operatorname{Tr}(x) .
$$

\subsection{Technology}

There is a representative firm that produces a single good using a Cobb-Douglas production function such that $Y=A K^{\alpha} N^{1-\alpha}$ where $\alpha$ is the output share of capital, $K$ and $L$ are the aggregate capital and aggregate labor input, and $A$ is the total factor productivity. Capital depreciates at a constant rate $\delta \in(0,1)$. The firm pays a proportional tax on capital income $\tau_{k}$. We assume a small open economy such that the after-tax return on assets, $r$, is exogenous. Therefore, in equilibrium, capital per worker is given by

$$
r=\left(1-\tau_{k}\right)\left(\alpha A(K / N)^{\alpha-1}-\delta\right)
$$

which determines the wage per efficient unit of labor services,

$$
w=(1-\alpha) A(K / N)^{\alpha} .
$$

We assume that the economy is in a stationary competitive equilibrium. The full definition of the equilibrium is provided in Section 3 of the Online Appendix.

\section{Calibration}

Our calibration strategy consists of two stages. In the first stage, we set the values of some parameters that can be determined based on independent estimates from the data or the existing literature. In the second stage, we calibrate the rest of the parameters by minimizing the distance between data targets and their model counterparts. 
Our goal is to quantify the impact of health inequality on lifetime earnings inequality. To do so we must first pin down the magnitudes of the various channels through which frailty impacts earnings and employment in the model. Recall that the five channels through which frailty operates are via its impact on: 1) mortality rates, 2) out of pocket medical expenditures, 3) labor productivity, 4) probability of successful DI application, and 5) disutility from working. The effect of frailty on the first three channels can be estimated directly from the data without using the model. As we describe in more detail below, we estimate these effects in the first stage of the calibration.

The effects of frailty on the probability of successful DI application and the disutility from working cannot be discerned directly from the data. ${ }^{33}$ These effects are, instead, determined in the second stage of the calibration by minimizing the distance between model and data moments. Specifically, the parameters governing DI eligibility and disutility from work are chosen by targeting the labor force participation rates and DI recipiency rates by age and frailty percentile groups shown in Figure 2. The moments are concentrated in the unhealthy tail of the frailty distribution since this is where the effects of frailty on labor supply and DI recipiency are most pronounced. Notice that this set of targeted moments includes labor force participation rates by frailty for both younger workers and workers over the age of 65 . This is intentional. The chance of successful DI application does not directly impact the labor supply choices of individuals after the age of 65. Thus, by targeting the dispersion in labor force participation rates by frailty for this age group we are able to separately identify frailty's impact on the disutility from work from its impact on successful DI application.

\subsection{Demographics and initial distributions}

We assume age $j=1$ corresponds to a 25 year-old and $J=70$ corresponds to a 94 year-old. Workers receive old-age social security and Medicare benefits at age $R=41$ (66 year-olds). This is also the age at which they no longer choose between working and applying for SSDI but instead choose between working and being retired.

Conditional survival probabilities at each age are estimated using HRS data and a probit regression. Mortality depends on a quadratic in frailty, a quadratic in age, education, and gender. The results of this estimation are presented in Section 4 of the Online Appendix. ${ }^{34}$ We adjust the value of the estimated constant so that population mortality is consistent with the year 2000 period life-table in Bell and Miller (2005). The population growth rate is set to $\nu=0.02$ so that the ratio of old (over 65) to young (65 and younger) is equal to 0.2 (this is consistent with the year 2000 U.S. Census).

The population is divided into three education groups: high school dropouts, high school graduates, and college graduates. The initial distribution of agents across the three groups is 12 percent high school dropouts, 52 percent high school graduates, and 36 percent college graduates based on the education distribution of 25-26 year-olds in our PSID sample.

Even though the fraction of individuals non-employed and on DI is only 2.3 percent

\footnotetext{
${ }^{33}$ We cannot directly estimate the probabilities of successful DI application because none of the datasets we use provide information on whether or not a respondent has applied for DI. We only see whether or not respondents are currently receiving DI benefits.

${ }^{34}$ Agents do not have a gender in the model. Instead, we compute the mortality rate of an agent by giving him the average gender in the population in year 2000 .
} 
at ages 24-26, it varies substantially across frailty and education. For this reason, we set the initial distributions of individuals across employment states (employed, non-employed, and DI beneficiary) by education and frailty percentile group to be consistent with their counterparts in the data. Section 4 of the Online Appendix provides the numbers.

\subsection{Preferences}

Individuals have utility over consumption, $c$, and suffer disutility from working which depends on their frailty, $f$. Period utility of workers is given by,

$$
u(c, l, f)=\frac{\left(c^{\mu}\left(1-\left[\phi_{0}+\phi_{1} f^{\phi_{2}}\right] l\right)^{1-\mu}\right)^{1-\gamma}}{1-\gamma}
$$

where $l \in\{0,1\}$ is equal to 1 if the individual is working and 0 otherwise. ${ }^{35}$

The parameters $\phi_{0}, \phi_{1}$, and $\phi_{2}$ determine how frailty affects the disutility of work. We assume $\phi_{0} \geq 0, \phi_{1} \geq 0$, and $\phi_{2} \geq 0$ so that the disutility of work is increasing in frailty. It also implies that the marginal utility of consumption declines as health deteriorates. This is consistent with empirical findings in Finkelstein et al. (2013). Moreover, in our benchmark calibration $\phi_{2}$ is larger than one, which implies that the marginal effect of increasing frailty is higher for more frail individuals. As we explained above, the parameters $\phi_{0}, \phi_{1}$, and $\phi_{2}$ are determined in the second-stage minimization. They are pinned down by the level and variation by age and frailty in the labor force participation rates of workers aged 25 to 84 .

The rest of the parameters are standard. For the benchmark calibration, we set $\gamma=2$ and $\mu=0.5$, which implies a coefficient of relative risk aversion of $1-(1-\gamma) \mu=1.5$. This is in the middle of the range of values used in the macro literature. ${ }^{36}$

\subsection{Labor productivity and job separation}

We estimate the labor productivity process, $\eta(j, f, s, \epsilon)$, separately for each education group using PSID and HRS data. For each group, labor productivity is the sum of a deterministic component and a stochastic component. The deterministic component consists of age and frailty effects. The stochastic component contains both a fixed effect and an AR(1) shock.

One concern when estimating the labor productivity process is selection bias. We do not observe hourly wages (our proxy for labor productivity) of those who do not work. If individuals whose frailty more negatively impacts their labor productivity are less likely to work, not controlling for selection will lead us to underestimate the impact of frailty on productivity.

To correct for potential selection bias, we estimate the labor productivity process in three steps. First, we use the system GMM dynamic panel estimator outlined in Section 2.1 and a selection correction procedure to estimate the effect of frailty on productivity.

\footnotetext{
${ }^{35}$ This utility function is very common in the literature. See, for example, Capatina (2015), De Nardi et al. (2017), French (2005), Pashchenko and Porapakkarm (2017) and Pashchenko and Porapakkarm (2019). The only difference is that in our model health enters the utility function via a smooth nonlinear function as a opposed to a jump variable.

${ }^{36}$ See Attanasio (1999) and Blundell and MaCurdy (1999) for surveys.
} 
Table 5: Estimated effect (\%) of one additional frailty deficit on log productivity (wage)

\begin{tabular}{lcccc}
\hline & HSD & HS & $\begin{array}{c}\text { CL } \\
\text { (frailty }\end{array}$ & 76th prctile) \\
& & & 0.0 & $\begin{array}{c}\text { CL } \\
\text { (frailty }=95 \text { th prctile) }\end{array}$ \\
\hline No bias correction & -4.2 & -2.5 & 0.0 & -2.6 \\
Bias correction & -4.4 & -2.7 & -2.8 \\
\hline
\end{tabular}

Second, removing the frailty effects from our productivity observations, we estimate the age effects via OLS. Third, using variance-covariance moments constructed with the final frailty residuals, we estimate the stochastic component via GMM.

To conduct the selection correction in the first step, we follow Al-Sadoon et al. (2019) who show that in system GMM, selection bias is mainly due to correlation of the fixed effects in the selection and outcome processes. To correct for this selection bias they propose first estimating a selection equation that includes fixed effects and an exclusion restriction. ${ }^{37}$ They then suggest including the estimated fixed effects as regressors in the outcome equation.

We use a fixed effect linear probability model of employment as our selection equation. We include the same set of regressors in our selection equation as in the outcome equation with the addition of exclusion restrictions. Following Low and Pistaferri (2015), we use "potential" government transfers interacted with frailty as our exclusion restrictions. "Potential" government transfers are defined as the sum of food stamps, AFDC/TANF payments, unemployment insurance benefits, and EITC payments that individuals would receive if they applied. These transfers vary across states. Moreover, they depend on marital status and number of kids (which also vary across individuals in our sample). Therefore, instead of using the amount of "potential" transfers as exclusion restrictions we use the interaction of state of residence, number of kids and martial status (a total of 436 combinations). These "potential" transfers do not directly impact individuals' wages or labor productivity but do create different work incentives for people with different frailty levels.

Once we have estimates of the first-stage fixed effects, we estimate the effect of frailty on log wages using the dynamic panel system GMM estimator. We consider two specifications of the frailty effect: linear and quadratic. In each specification, for each individual, log wages is assumed to be a function of two lags of log wages, lagged frailty or a quadratic in lagged frailty interacted with education, a fixed effect, and the individual's estimated fixed effect from the first stage regression. We find evidence of quadratic frailty effects for the college group but not for the non-college groups. ${ }^{38}$ Given these findings, we use the linear specification for high-school dropouts and high-school graduates, and the quadratic specification for college graduates.

Table 5 reports the estimated effects of accumulating one additional deficit on log wages for each education group with and without controlling for selection. ${ }^{39}$ Consistent with our

\footnotetext{
${ }^{37}$ An exclusion restriction is a variable that impacts the selection process but not the outcome process. In our case, a valid exclusion restriction should impact employment but not labor productivity or wages.

${ }^{38}$ See Section 4 of the Online Appendix for details, as well as, the full set of estimation results.

${ }^{39}$ There are two important differences between theses estimations and those in Section 2.1. First, the estimation in this section is done only on a sample of men. Second, we treat frailty as exogenous in these regressions given our earlier finding on the absence of reverse causality. In the Online Appendix Section 4
} 
findings in Section 2.1, the negative effects of frailty on wages are decreasing with education on average and only present for college graduates who are already in poor health. One additional deficit reduces wages by 4.4 percent for high school dropouts and 2.7 percent for high school graduates. ${ }^{40}$ The estimated effect for college graduates with frailty below the 76th percentile is zero. Starting at the 76th percentile, the effect increases at an increasing rate. As the right column of the table reports, accumulating one additional deficit when at the 95th percentile of the frailty distribution reduces a college graduates frailty by 2.8 percent. Notice that, consistent with our concerns, the effect of frailty on wages is slightly smaller when not controlling for selection bias.

Given these estimation results, we next remove the effects of frailty from our log wage observations. Then, to obtain the deterministic age effects, separately for each education group, we regress the adjusted log wages on a cubic polynomial in age and year dummies. Finally, we use the residuals from this regression to construct a set of variance-covariance moments. As in Guvenen (2009), we use these moments to estimate the stochastic component via GMM. For these last two steps, we group together high school dropouts and high school graduates in order to take advantage of larger sample sizes. The implication of this is that, while the effect of frailty on productivity is education group specific, the age effects and stochastic component are the same for both high school dropouts and high school graduates. The estimation results are presented in Section 4 of the Online Appendix.

Our productivity process estimation strategy doesn't capture the effects of severe lifelong disability on productivity. To capture these effects we assume that a small fraction of individuals, those who are already DI beneficiaries at age 25 , have permanent zero productivity. As we stated in Section 4.1, the fraction of such individuals varies by education and initial frailty percentile group. Overall, 2.3 percent of 25 year-olds are assigned to this group. These individuals are primarily high school dropouts and are concentrated in the top percentiles of the frailty distribution.

Finally, the job separation rate is set to $\sigma=15 \%$, which is the average (annual) rate of layoffs and discharges between 2005 and 2007 according to the Jobs Opening and Labor Turnover Survey (JOLTS) by the Bureau of Labor Statistics (BLS).

\subsection{Frailty and medical expenditures}

Our specification and estimation of the frailty process, $\psi\left(j, s, \varepsilon_{f}\right)$, using PSID data follows closely that in Hosseini et al. (forthcoming). We assume that there is a positive mass of individuals with zero frailty at age 25. Each period, these individuals move to a positive frailty value with a probability that depends on their education and a quadratic in age. Once positive, an individual's frailty never goes back to zero. ${ }^{41}$ We use a probit regression to estimate the conditional probabilities of positive frailty by age and education. ${ }^{42}$

we show that the estimated effects of frailty are robust to making frailty endogenous.

${ }^{40}$ Using a different measure of health to ours, Low and Pistaferri (2015) also estimate the effect of poor health on labor productivity for non-college men. In a rough comparison, we find that our effects are similar in magnitude, albeit slightly larger, as compared to theirs. Details are provided in Section 4 of the Online Appendix.

${ }^{41}$ Less than 1 percent of individuals in our PSID sample with positive frailty have zero frailty next period.

${ }^{42}$ The estimated parameters are reported in Section 4 of the Online Appendix. 

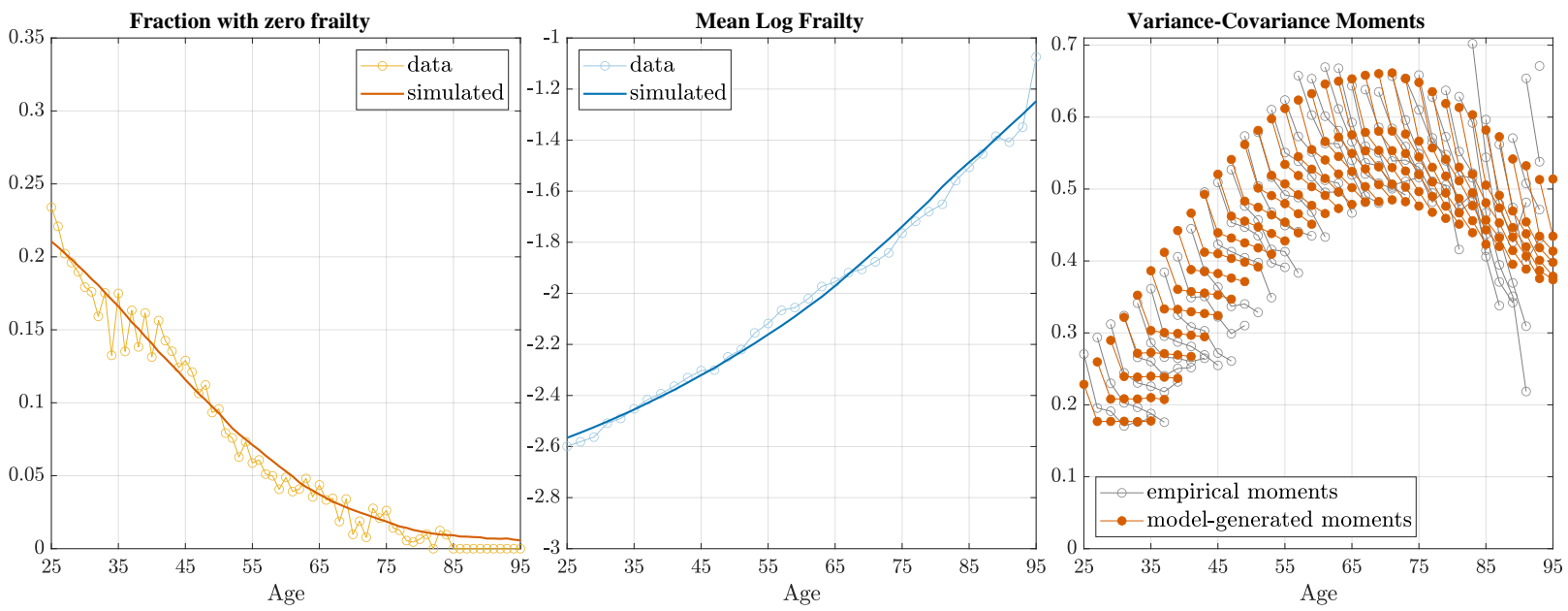

Figure 3: Estimation targets: auxiliary simulation model vs PSID data for high school graduates. Left panel is the fraction with zero frailty by age, middle panel is mean log frailty by age for those with nonzero frailty, and right panel is the age-profile of the variance and covariances of log frailty residuals (the stochastic component of log frailty).

For individuals with positive frailty, log frailty is given by the sum of a quartic age polynomial and a stochastic component. The stochastic component consists of an AR(1) shock, a transitory shock, and a fixed effect. The $\mathrm{AR}(1)$ shock captures persistent health events such as developing diabetes, while the transitory shock captures acute ones such as a temporary inability to walk due to a broken leg. We find that there are large differences in frailty dynamics by education. For this reason, we estimate the log frailty process separately for each education group.

Frailty and mortality are highly correlated. Thus, when estimating the nonzero frailty process, it is important to control for selection bias due to mortality. To this end, we estimate the frailty processes using an auxiliary simulation model and the method of simulated moments (MSM). The auxiliary simulation model simulates the frailty dynamics described above together with the mortality rates by age and education given by the specification in Section 4.1. For each education group, the coefficients of the age polynomial are determined by targeting the age profile of log frailty for 25 to 95 year-old PSID respondents. The variance and persistence of the $\mathrm{AR}(1)$ shock, variance of the transitory shock, and variance of the fixed effect are determined by targeting variance-covariance moments by age of the log frailty residuals. ${ }^{43}$

Figure 3 shows the estimation results for high school graduates (the largest education group in our sample). ${ }^{44}$ The left panel shows the fraction of high school graduates with zero frailty by age in the data and in the simulation of the model. The middle figure shows the age profile of mean log frailty targeted in the data and the model counterpart. The right panel shows the age profile of the variance-covariance moments in the model and the data. Notice that our estimated frailty process is able to generate autocovariance patterns that

\footnotetext{
${ }^{43}$ The estimated parameters are reported in Section 4 of the Online Appendix.

${ }^{44}$ The estimation results for the other two education groups are shown in Section 4 of the Online Appendix.
} 
Table 6: Parameters chosen outside the model

\begin{tabular}{clc}
\hline Parameter & Description & Values/source \\
\hline Demographics & & \\
$J$ & maximum age & $70(94 \mathrm{y} / \mathrm{o})$ \\
$R$ & retirement/SS eligibility age & $41(66 \mathrm{y} / \mathrm{o})$ \\
$\nu$ & population growth rate & 0.02 \\
Preferences & curvature of utility function & 2 \\
$\gamma$ & weight on consumption & 0.5 \\
$\mu$ & & \\
Job Separation & annual layoffs/separations in JOLTS & 0.15 \\
$\sigma$ & & \\
Technology & capital share & 0.33 \\
$\alpha$ & depreciation rate & 0.07 \\
$\delta$ & return on assets & 0.04 \\
$r$ & & \\
Government policies & social security and Medicare tax rates & $0.124,0.029$ \\
$\tau_{S S}, \tau_{\text {med }}$ & capital tax & 0.3 \\
$\tau_{K}$ & tax progressivity & 0.036 \\
$\tau$ & SSI payment (\% of ave. earning) & 13 \\
$\underline{b}$ & minimum consumption (\% of ave. earnings) & 11 \\
$\underline{c}$ & government purchases (\% of GDP) & 17.5 \\
\hline$G$ & &
\end{tabular}

are very similar to those in the data.

We estimate out-of-pocket medical expenditures separately by education and labor market status: employed, non-employed, and on Medicare (which includes both retirees and those who are on DI). To capture the nonlinear effect of frailty on medical spending, we assume that $\log$ out-of-pocket medical expenditures are determined by a cubic in age and a cubic in frailty. We estimate the coefficients of these functions using data from MEPS. Note that although we do not include any randomness directly in this formulation, the outof-pocket medical expenditure is random through its dependence on frailty. The results of these estimations are presented in Section 4 of the Online Appendix.

\subsection{DI application}

The SSDI application process is complex and lengthy. Moreover, even though the probability of successfully obtaining benefits is generally higher for individuals in worse health, the outcome is uncertain. ${ }^{45}$ The process starts with a 5 month waiting period during which applicants are not allowed to be gainfully employed. After this initial period, applicants' cases are reviewed by the Disability Determination Service (DDS) review board. The most definite cases are approved for benefits at this point. For instance, individuals with one of 100

\footnotetext{
${ }^{45}$ See French and Song (2014) and the references therein for a detailed overview of the program.
} 
specifically listed and verifiable medical conditions are usually given benefits at this stage. Less definite cases are usually denied. However, denied applicants can request reconsideration by the DDS office. After a 60 day waiting period, further denials can be again appealed. Such appeals are assessed by an administrative law judge (ALJ) after a period of roughly one year. Judges have considerable latitude in assessing appeals. Applicants whose appeals are denied, can continue to appeal for multiple rounds with approximately a one year turnaround time between appeal and decision each round. Alternatively, denied applicants can end the appeals process and start over applying for benefits by submitting a new application.

French and Song (2014) document that by one year after initial application, about 50 percent of applicants will usually have been awarded benefits. After this point, the probability of obtaining benefits continually declines in the number of years since initial application (see the middle panel of Figure 4). After 10 years, only 70 percent of applicants who continually appeal or reapply are approved. Thus, individuals can spend years trying to successfully get on DI.

Motivated by the description above, we assume that the probability of successful DI application depends on an individual's frailty, $f$, and the number of periods the individual has subsequently applied for DI, $n_{a}$. Specifically, we set

$$
\theta\left(f, n_{a}\right)=\min \left\{1, \kappa_{0} f^{\kappa_{1}} n_{a}^{\kappa_{2}}\right\} .
$$

The parameters $\kappa_{0}, \kappa_{1}$, and $\kappa_{2}$ are determined in the second stage of the calibration. Both $\kappa_{0}$ and $\kappa_{1}$ are identified by targeting DI recipiency rates by age and frailty in the minimization. Parameter $\kappa_{2}$ is identified off the rate at which the probability of obtaining benefits declines in the years since initial application. In fact, we include $n_{a}$ in the probability function to ensure that the model will match this rate. Matching this rate is important as it impacts the decision to continue to apply for DI or reenter the labor force. As Table 7 shows, however, the minimization procedure places little weight on $n_{a}$. This is because the probability of successfully obtain DI is increasing and convex in frailty. As a result, the applicant pool naturally becomes more and more selected towards healthier, and hence less likely to be successful, applicants as the number of periods since initial application increases.

\subsection{Policy parameters}

For old-age social security and SSDI benefits, we use the social security benefit formula for primary insurance amount:

$$
\widetilde{S S}(\bar{e})= \begin{cases}0.9 \bar{e}, & \bar{e} \leq 0.2 \bar{e}_{a} \\ 0.18 \bar{e}_{a}+0.33\left(\bar{e}-0.2 \bar{e}_{a}\right), & 0.2 \bar{e}_{a}<\bar{e} \leq 1.25 \bar{e}_{a} \\ 0.5265 \bar{e}_{a}+0.12\left(\bar{e}-1.25 \bar{e}_{a}\right), & 1.25 \bar{e}_{a}<\bar{e}\end{cases}
$$

where $\bar{e}_{a}$ is the average earnings in the economy. The SSI program provides an income floor to individuals eligible for either social security retirement or DI benefits. To capture SSI we assume that

$$
S S(\bar{e})=\max \{\widetilde{S S}(\bar{e}), \underline{b}\},
$$

where $\underline{b}$ is 13 percent of average earnings which is the ratio of the maximum annual Federal SSI payment to male average earnings in 2000. 
Table 7: Parameters calibrated using the model

\begin{tabular}{|c|c|c|c|}
\hline Parameters & Description & & Values \\
\hline \multicolumn{4}{|l|}{ Preferences } \\
\hline$\beta$ & discount factor & & 0.982 \\
\hline \multicolumn{4}{|l|}{ Policy } \\
\hline$\lambda$ & HSV tax parameter(level) & & 0.908 \\
\hline \multicolumn{4}{|l|}{ Disutility of work } \\
\hline$\phi_{0}$ & level & & 0.64 \\
\hline$\phi_{1}$ & frailty effect & & 2.8 \\
\hline$\phi_{2}$ & frailty effect & & 5.5 \\
\hline \multicolumn{4}{|l|}{ Prob. of successful DI application } \\
\hline$\kappa_{0}$ & level & & 179 \\
\hline$\kappa_{1}$ & frailty effect & & 5.9 \\
\hline$\kappa_{2}$ & number of attempts effect & & 0.6 \\
\hline \multicolumn{2}{|l|}{ Targeted Moments } & Data & Model \\
\hline \multirow{2}{*}{\multicolumn{2}{|c|}{$\begin{array}{l}\text { Wealth-earnings ratio } \\
\text { Federal income tax }(\% \text { of GDP) }\end{array}$}} & 3.2 & 3.2 \\
\hline \multirow{2}{*}{\multicolumn{2}{|c|}{$\begin{array}{l}\text { Federal income tax ( } \% \text { of GDP) } \\
\text { LFP rates by frailty percentile group and age }\end{array}$}} & 8 & 8 \\
\hline & ip and age & \multicolumn{2}{|c|}{ Figure 4} \\
\hline \multicolumn{2}{|c|}{ DI recipiency rates by frailty percentile group and age } & \multirow{2}{*}{\multicolumn{2}{|c|}{$\begin{array}{l}\text { Figure } 4 \\
\text { Figure } 4\end{array}$}} \\
\hline \multicolumn{2}{|c|}{$\begin{array}{l}\text { Relative DI success rates } \\
\text { las }\end{array}$} & & \\
\hline
\end{tabular}

The tax function $T(\cdot)$ has three components. One is a nonlinear component mimicking the U.S.income tax/transfer system. One is a social security payroll tax component consisting of a proportional tax that is subject to a maximum taxable earnings cap. And, one is a proportional Medicare payroll tax. We model the nonlinear component of the tax function in the fashion of Benabou (2002) and Heathcote et al. (2017). That is, the tax function $T(\cdot)$ is given as follows,

$$
T(e)=e-\lambda e^{1-\tau}+\tau_{s s} \min \left\{e, 2.47 \bar{e}_{a}\right\}+\tau_{\text {med }} e .
$$

Here, $\tau$ controls the progressivity of the tax function and is set to 0.036 based on the estimate by Guner et al. (2014). We choose the value of $\lambda$ in the second-stage of the calibration to match the total federal income tax receipts as a share of GDP in the U.S. data.

The social security payroll tax rate is set to $\tau_{s s}=0.124$ and the Medicare tax rate is set to $\tau_{\text {med }}=0.029$. There is also a capital tax, $\tau_{K}=0.3$, which is paid by the firm and set based on Gomme and Rupert (2007). The minimum consumption level, $c_{m i n}$, is set to 11 percent of average earnings. ${ }^{46}$ Finally, we set exogenous government purchases, $G$, to 17.5 percent of GDP. We hold this ratio fixed in all counterfactual experiments we run.

\footnotetext{
${ }^{46}$ See Kopecky and Koreshkova (2014) for details and a review of the literature.
} 

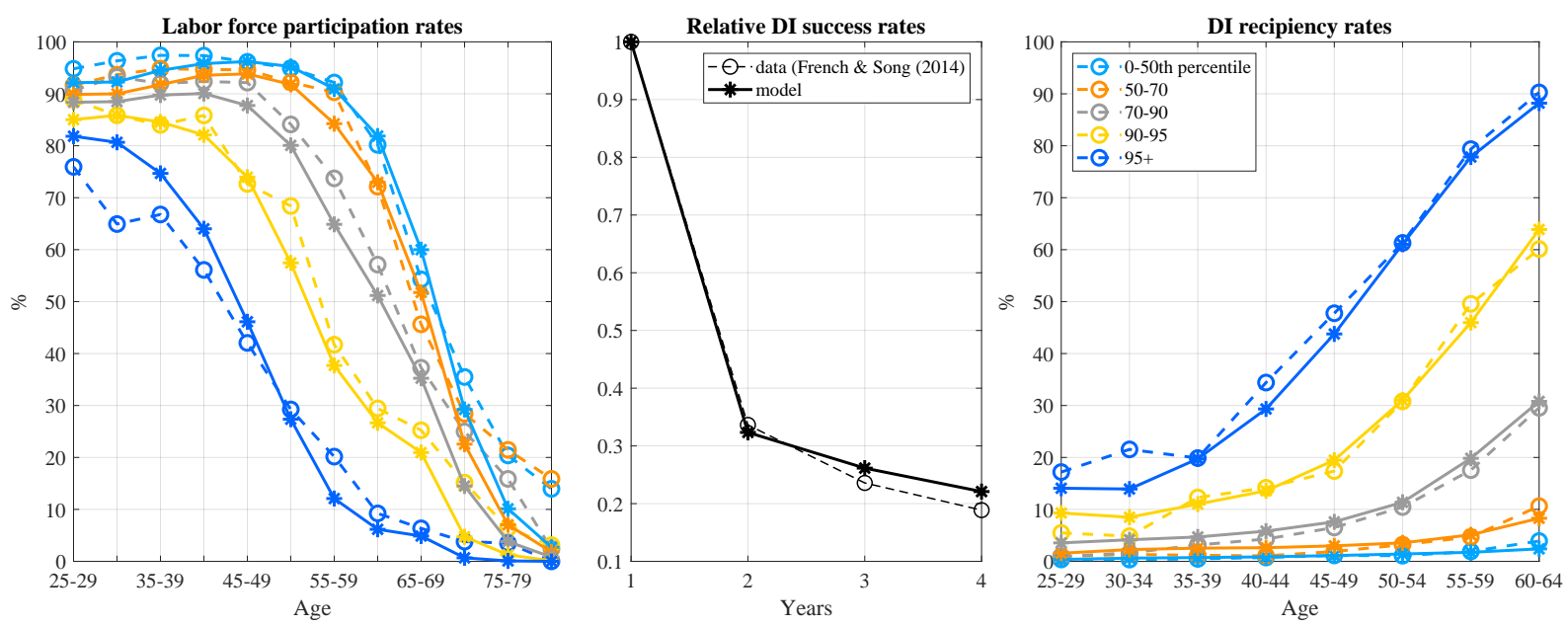

Figure 4: Calibration targets: model versus data. Solid (dashed) lines are the model (data). The left panel shows labor force participation rates (data source is PSID), the right panel shows DI recipiency rates (data source is MEPS and Social Security Administration), and the middle panel shows relative rates of success in DI application by years since initially applied (data moments are based on findings reported by French and Song (2014)). The rate for the first year is normalized to 1.

\subsection{Technology}

We assume a small open economy and set $r=0.04$. The capital share $\alpha$ is set to 0.36 . We normalize aggregate TFP, given by $A$, to 1 , and choose $\beta$ in the second stage such that the model generates a wealth-to-earnings ratio of $3.2 .{ }^{47}$ The depreciation rate is set to $\delta=0.07$. This is based on calculations in Gomme and Rupert (2007). ${ }^{48}$

In the model, employed workers who just came back from non-employment suffer a wage penalty which mimics the forgone earnings during job search within the period. According to the U.S. Bureau of Labor Statistics, the average duration of unemployment in the U.S. was approximately 15-20 weeks between 2000 and 2007. Therefore, we set the wage penalty to be one third of one year's earnings.

\section{Assessment}

Tables 6 and 7 summarize the baseline model parameterization. Figure 4 provides a comparison of the labor force participation rates, DI recipiency rates, and relative DI success rates targeted in the data with the model counterparts. All targeted moments are reasonably matched. Notice that although the model slightly understates the labor force participation

\footnotetext{
${ }^{47}$ In choosing this moment we follow Hong and Ríos-Rull (2012) and only target the wealth-to-earnings ratio of the bottom 95 percent.

${ }^{48}$ Gomme and Rupert (2007) calculate depreciation rates for four different sectors (market structures, equipment and software, housing, and consumer durables). We use a weighted average of their calculations. To do this we weight depreciation in each sector by the shares of capital in that sector as reported in their paper.
} 
Table 8: Labor force participation and DI recipiency rates by education, ages 25-64 (\%)

\begin{tabular}{ccccccc}
\hline & \multicolumn{2}{c}{ HSD } & \multicolumn{2}{c}{ HS } & \multicolumn{2}{c}{ CL } \\
& Data & Model & Data & Model & Data & Model \\
\hline Labor force participation rates & 78 & 76 & 87 & 86 & 94 & 94 \\
DI recipiency rates & 11.8 & 12.3 & 6.6 & 7.4 & 2.7 & 2.6 \\
\hline
\end{tabular}

rates of workers ages 75-84, it matches well the level and dispersion in labor force participation rates of workers aged $65-74$. This is important as it is these rates relative to the rates of those under 65 that determines the disutility from work parameters.

To assess the model's performance with regards to non-targeted moments, we look at labor force participation and DI recipiency rates across different education groups. Table 8 shows the overall participation and DI recipiency rates by education group. The top panel shows that the model does reasonably well in matching overall participation rates by education. The bottom panel shows that the model slightly understates the DI recipiency rate for college graduates and slightly overstates it otherwise.

To inspect the fit by education further, we report the labor force participation and DI recipiency rates by age and frailty percentile groups separately for each education group. The labor force participation rates are presented in Figure 5 and the DI recipiency rates are presented in Figure 6. From these figures we see that the model performs reasonably well in capturing the pattern of labor force participation for each education group. In particular, it captures well the reduced dispersion in both labor force participation rates and DI recipiency rates by frailty as education increases. For those in the top 5 percent of the frailty distribution, the model slightly overstates the labor force participation rates of the college graduates. Likewise, the model slightly understates their DI recipiency rates.

As a final assessment of the baseline parameterization, we look at the impact of DI benefit denial on labor force participation. In the baseline model, 31 percent of individuals denied benefits in their first year after application are working three years later. For individuals ages 35 to 64 , the fraction is 28 percent and for individuals ages 45 to 64 the fraction is 26 percent. ${ }^{49}$ These rates are broadly consistent with estimates of the impact of benefit denial on labor force participation in the empirical literature. For instance, French and Song (2014) find that in the 1990's benefit denial at the ALJ stage (about 2 years after application) increased the labor force participation rates of 35 to 64 year olds three years later by 26 percent and Maestas et al. (2013) find that in the early 2000's benefit denial at the DDS stage (about 1 year after application) increased the labor force participation rates of 18 to 64 year olds three years later by 27 percent. Similarly, Von Wachter et al. (2011) show that the labor force participation rates of 45-64-year-old males were 31 percent higher three years after benefit denial in 1982 and 35 percent higher three years after benefit denial in 1997. Finally, in earlier work, Bound (1989) looks at the impact of benefit denial on 45-64-year-old males in 1977 and finds that it increased the fraction working full-time by 32 percent.

\footnotetext{
${ }^{49}$ See Section 4 of the Online Appendix for more information on the calculation of these statistics.
} 

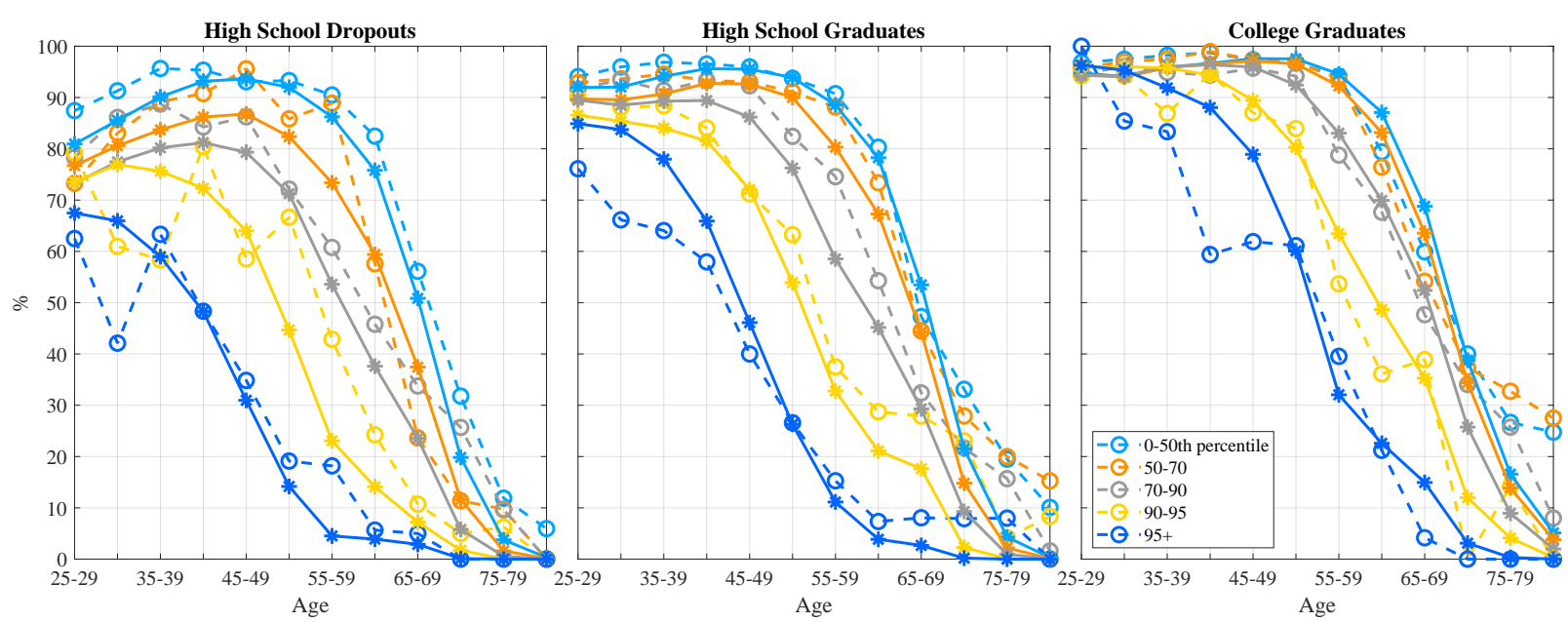

Figure 5: Calibration assessment: model versus data. Solid (dashed) lines are the model (data). The panels show the labor force participation rates by frailty percentile groups and age for each education group: high school dropouts, high school graduates, and college graduates. Source for the data is PSID.

\section{Quantitative Exercise}

In this section we use the calibrated model to assess the impact of health inequality on lifetime earnings inequality. ${ }^{50}$ To do this we conduct the following experiment. We consider a counterfactual economy in which everyone has the average frailty profile. Giving all individuals in the economy the average frailty profile removes all cross-sectional variation in frailty conditional on age. In particular, it removes heterogeneity in frailty due to education and individuals' fixed frailty types. It also removes the heterogeneity in frailty due to the persistent and transitory frailty shocks. We refer to the counterfactual economy as the no-frailty-heterogeneity ( $\mathrm{NFH}$ ) economy. We compare the inequality in lifetime earnings at different ages in the NFH economy and the benchmark. For each individual, our measure of lifetime earnings at each age is simply that individual's accumulated earnings to date.

Removing health inequality significantly reduces inequality in lifetime earnings at older ages. Figure 7a shows the age-profile of the variance of log lifetime earnings in the benchmark economy and the NFH economy. The variation in lifetime earnings is almost the same in the two economies at younger ages. However, between ages 35 and 70, the variance of $\log$ lifetime earnings increases more rapidly with age in the benchmark economy. As a result, there is less variation in lifetime earnings in the NFH economy starting around age 40. As reported in Table 9, at age 45 the variance of log lifetime earnings is 13.1 percent lower in the NFH economy relative to the benchmark. The relative difference peaks at age 65 when the variance of log lifetime earnings is 30.4 percent lower.

Removing health inequality, not only reduces the variance of log lifetime earnings but it also leads to a smaller fraction of individuals with zero lifetime earnings at each age.

\footnotetext{
${ }^{50}$ We focus on lifetime earnings given that much of the impact of health on earnings comes via permanent reductions in labor force participation. Another paper which studies the lifetime earnings distributions in the U.S. is Guvenen et al. (2017).
} 

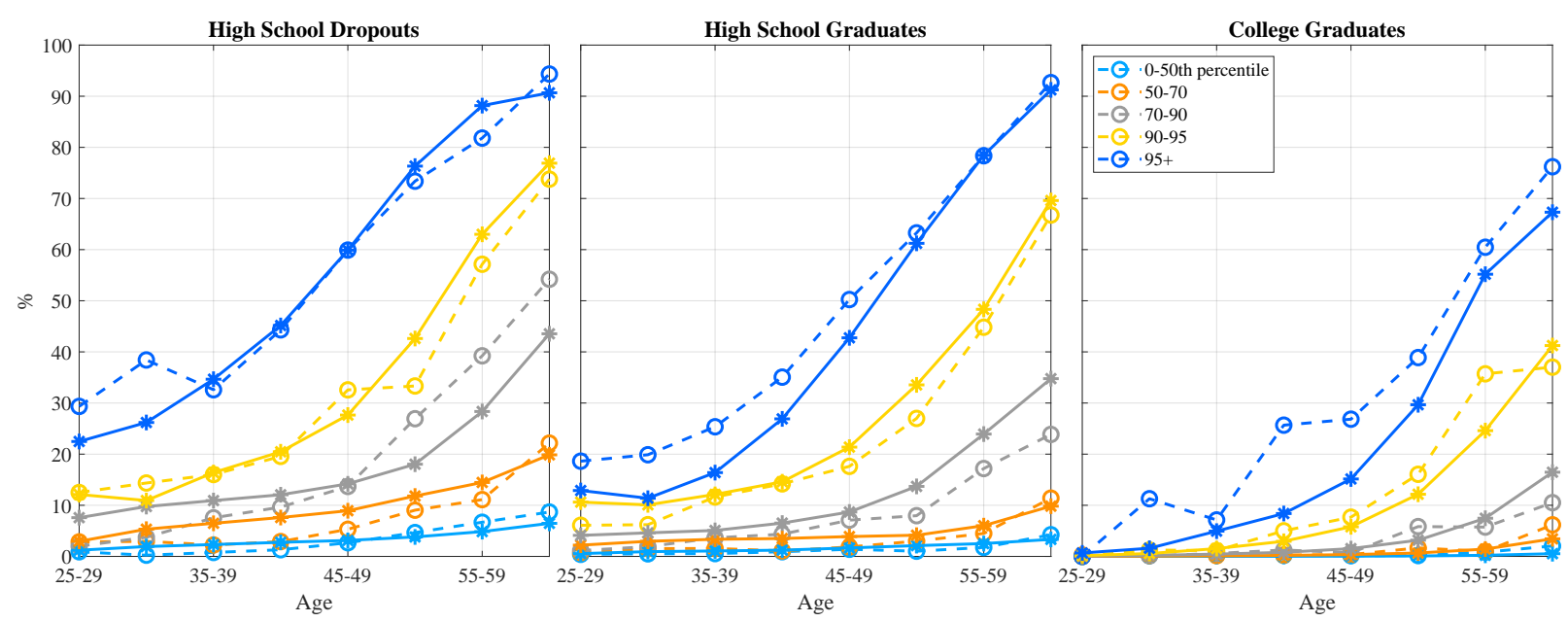

Figure 6: Calibration assessment: model versus data. Solid (dashed) lines are the model (data). The panels show the DI recipiency rates by frailty percentile groups and age for each education group: high school dropouts, high school graduates, and college graduates. Source for the data is MEPS and Social Security Administration.

As Figure 7b shows, the fraction of these individuals in the benchmark and NFH economy declines rapidly between ages 25 and 30 after which it remains small. Notice that, while small in both, the fraction of individuals with zero lifetime earnings is considerably lower in the NFH economy.

Health inequality in the model is due to both initial heterogeneity in frailty, captured by fixed effects and education, and idiosyncratic frailty shocks. To understand the relative importance of each of these components for lifetime earnings inequality, we conduct two related counterfactual experiments and report the results in Table 9. The middle panel of the table shows the variance of log lifetime earnings for a counterfactual economy that is identical to the benchmark, except that there are no frailty shocks. All inequality in frailty in this economy is due to initial fixed heterogeneity. The bottom panel shows the same results for an economy that does not feature any initial heterogeneity in frailty due to fixed effects or education. All the inequality in frailty in this counterfactual is driven by frailty shocks. As the table shows, frailty shocks have a larger impact on lifetime earnings inequality than initial frailty heterogeneity. While frailty shocks are more important at all four ages reported in the table, their relative importance peaks at age 55 when their effect on lifetime earnings inequality is nearly double. The variance of log lifetime earnings at age 55 is 12.4 percent lower in the economy without initial frailty heterogeneity and 24.0 percent lower in the economy without frailty shocks. In this sense, frailty shocks account for about two-thirds of the effect of health inequality on lifetime earnings inequality at age 55 and similarly at age 65 . Notice that at age 45, removing frailty shocks reduces lifetime earnings inequality more than removing all frailty heterogeneity. This is because removing only shocks versus both shocks and fixed effects impacts the pattern of labor supply over the lifecycle. ${ }^{51}$ With no frailty heterogeneity, individuals slightly reduce labor supply at young

\footnotetext{
${ }^{51}$ See Section 5 of the Online Appendix.
} 


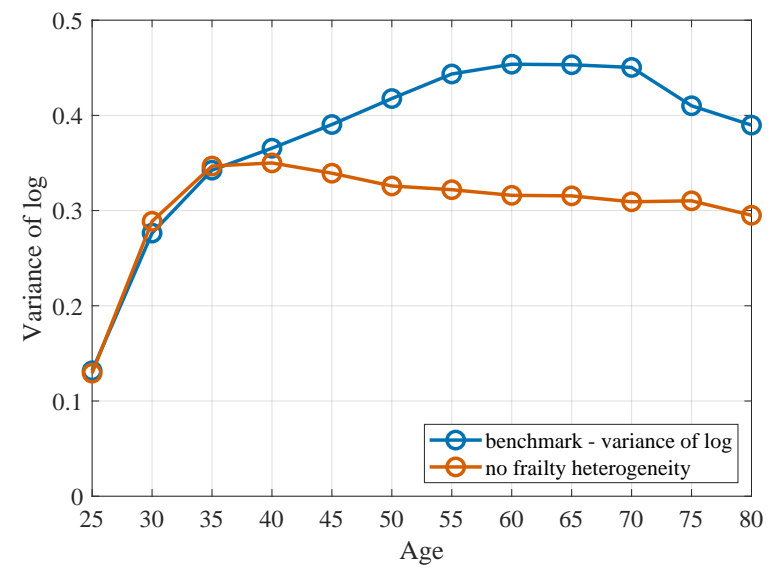

(a) Variance of log lifetime earnings.

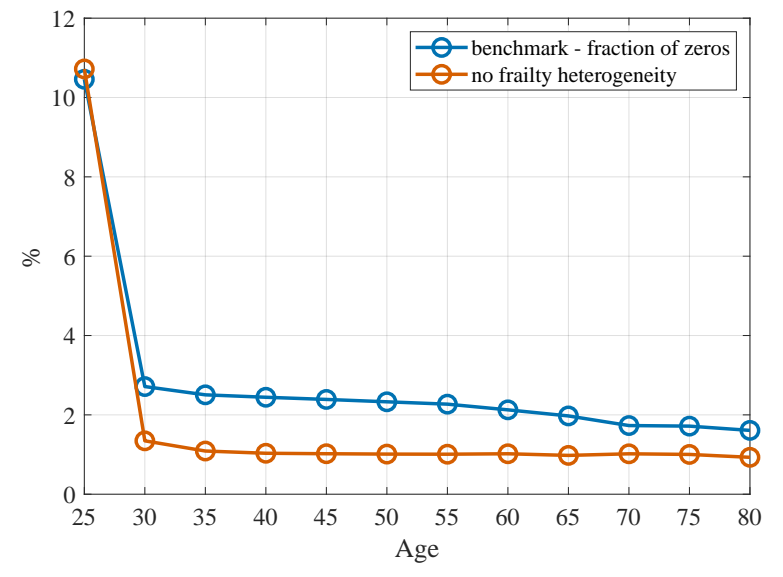

(b) Fraction with zero lifetime earnings.

Figure 7: The variance of log lifetime earnings (left) and the fraction of individuals with zero lifetime earnings (right) in the benchmark economy (blue) and the no-frailty-heterogeneity economy (red).

ages and substantially increase it at older ages when productivity is highest. However, when only shocks are removed, individuals with higher initial frailty levels have an incentive to work more when young and apply for DI programs when older. This incentive leads to a larger decline in lifetime earnings inequality at younger ages in the economy with no frailty shocks as compared to the NFH economy.

Almost all of the difference between the variance of log lifetime earnings in the benchmark and the NFH economy is due to higher earnings at the bottom of the distribution in the NFH economy. Figure 8 displays the ratios of lifetime earnings at the 5th, 10th, 90th, and 95th percentile relative to the median by age in the the two economies. Notice that, after age 30, there are large differences across the two economies between the ratios of the 5th and 10th percentiles relative to the median. In contrast, there are little differences in the ratios of the 90 th and $95 \mathrm{th}$. Individuals in the bottom of the lifetime earnings distribution in the benchmark economy are more likely to be in poor health. They are also more likely to be less educated which means they face larger negative effects of poor health on their labor productivity. Giving these individuals the average frailty profile increases both their wages and their labor supply. In contrast, individuals at the top of the lifetime earnings distribution in the benchmark economy are mostly college-educated and healthy. As a result, giving these individuals the average frailty profile has little effect on their earnings.

\subsection{Breaking down the effect of health inequality}

Recall that there are five channels through which frailty can affect earnings inequality in the model: DI acceptance probabilities, labor productivity, disutility of work, amount of out-ofpocket medical expenditures, and mortality risk. How important are each of these channels for generating the differences in the variance of log lifetime earnings' profiles between the benchmark and NFH economies?

To assess the relative importance of each channel, we consider five additional counter- 
Table 9: Variance of log lifetime earnings: frailty shocks versus initial frailty heterogeneity.

\begin{tabular}{lcccc}
\hline & age 45 & age 55 & age 65 & age 75 \\
\hline Benchmark & 0.390 & 0.443 & 0.453 & 0.410 \\
No frailty heterogeneity (NFH) & 0.339 & 0.322 & 0.315 & 0.310 \\
$\% \Delta$ relative to benchmark & -13.1 & -27.4 & -30.4 & -24.3 \\
No frailty shocks & 0.338 & 0.337 & 0.349 & 0.346 \\
$\% \Delta$ relative to benchmark & -13.5 & -24.0 & -22.9 & -15.7 \\
No frailty fixed effect & 0.349 & 0.388 & 0.392 & 0.367 \\
$\% \Delta$ relative to benchmark & -10.5 & -12.4 & -13.5 & -10.6 \\
\hline
\end{tabular}

Note: In the "No frailty heterogeneity" counterfactual all individuals have the average frailty age profile. "No frailty shocks" removes ex post shocks but retains all fixed-effect heterogeneity. "No frailty fixed effect" removes fixed effect heterogeneity but retains all shocks.

Table 10: Variance of log lifetime earnings: different frailty channels.

\begin{tabular}{lcrrr}
\hline & \multicolumn{4}{c}{$\% \Delta$ relative to benchmark } \\
& age 45 & age 55 & age 65 & age 75 \\
\hline NFH in DI & -0.6 & -14.2 & -21.0 & -19.9 \\
NFH in Labor Prod. & -2.3 & -3.7 & -4.1 & -4.3 \\
NFH in Disutility & -0.4 & -0.8 & -1.0 & -0.9 \\
NFH in Med. Exp. & -0.1 & -0.2 & -0.0 & 0.0 \\
NFH in Mortality & -0.9 & 0.3 & 8.3 & 5.9 \\
\hline
\end{tabular}

Note: Each row shows the percentage change in the variance of log lifetime earnings in the counterfactual economy relative to the benchmark. Each counterfactual is identical to the benchmark expect that there is no frailty heterogeneity in the listed channel. Instead, the impact of frailty via that channel is determined by the average frailty age profile.

factual economies. Each economy is identical to the benchmark expect that, for one of the five channels, the impact of frailty is determined by the average frailty profile instead of a person's individual profile. Specifically, in counterfactual economy 1, labelled "NFH in DI", individuals' probability of successful DI application is determined by the average frailty profile. In counterfactual economy 2, labelled "NFH in Labor Productivity", individuals' labor productivity is determined by the average frailty profile. In counterfactual economy 3, "NFH in Disutility", disutility from working is determined by the average frailty profile. In counterfactual economy 4, "NFH in Medical Expenditure", out-of-pocket medical expenditures are determined by the average frailty profile. Finally, in counterfactual economy 5 , "NFH in Mortality", mortality rates are determined by the average frailty profile.

The results of this decomposition exercise show that, according to the model, the DI program (SSDI and SSI) is the most important channel through which health inequality generates lifetime earnings inequality. Table 10 presents the differences in the variances of log lifetime earnings between the benchmark and each counterfactual economy at four 


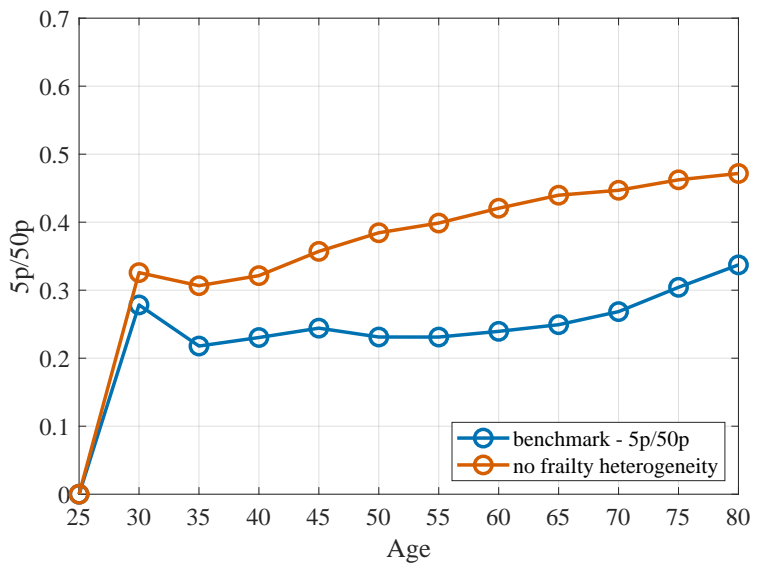

(a) 5th percentile to median

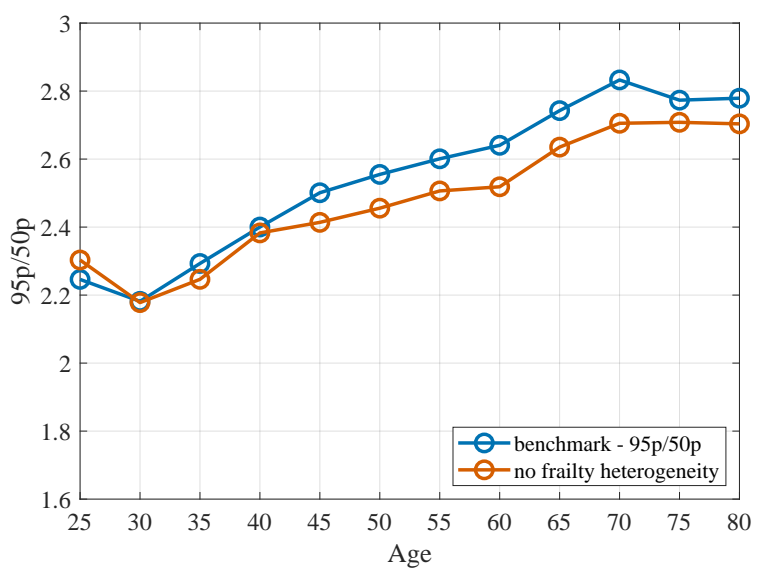

(c) 95 th percentile to median

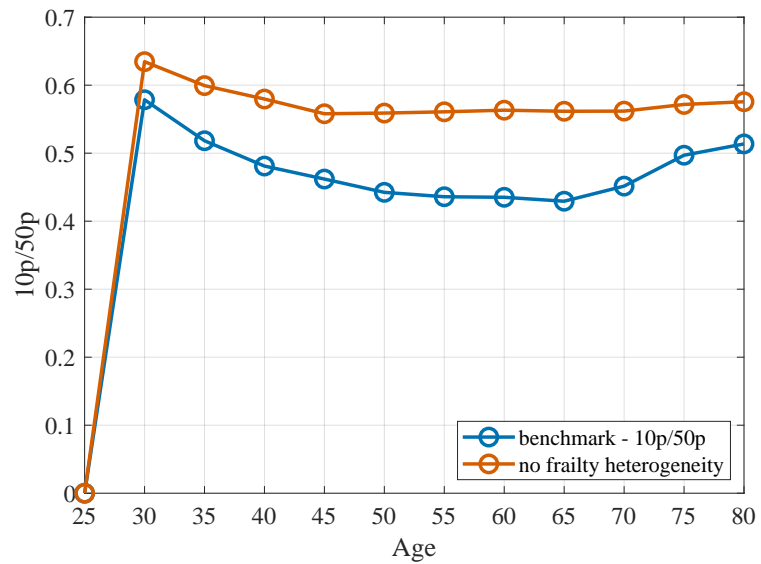

(b) 10th percentile to median

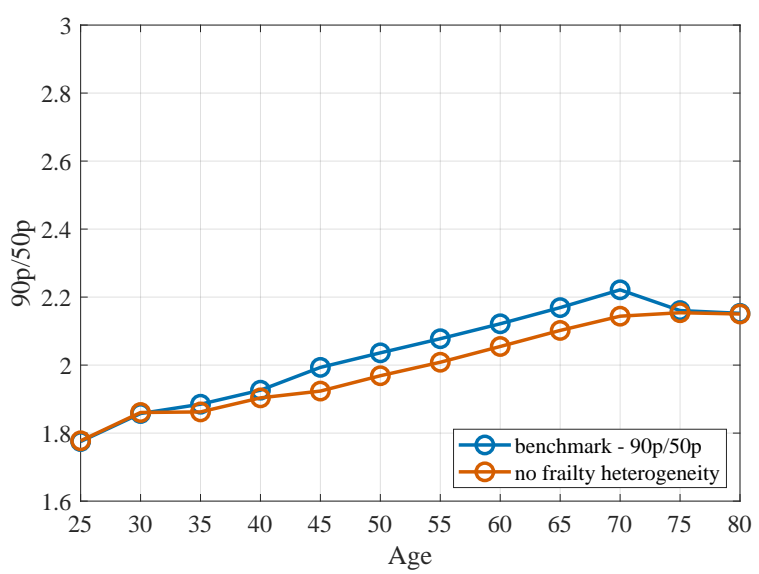

(d) 90 th percentile to median

Figure 8: Inequality in lifetime earnings in the benchmark economy (blue) and the no-frailtyheterogeneity economy (red).

ages. Notice that the labor productivity channel has the largest impact on lifetime earnings inequality at younger ages. Shutting down this channel reduces lifetime earnings inequality at age 45 by 2.3 percent, whereas shutting down the DI channel only decreases lifetime earnings inequality by 0.6 percent. However, by age 55 , the primary channel through which health inequality generates lifetime earning inequality is the DI channel. Shutting down the DI channel, reduces lifetime earnings inequality by 14.2 percent at age 55 . In contrast, shutting down the labor productivity channel, the second most important channel, reduces it by only 3.7 percent. At age 65, removing the DI channel reduces lifetime earnings inequality by 21.0 percent, more than four times the effect of removing the labor productivity channel.

Why does shutting down the DI channel have such a small effect on lifetime earnings inequality at age 45 as compared to older ages? While at older ages, in the benchmark economy, the DI program creates strong work disincentives for frail individuals, it has the opposite effect on very young frail people. Young frail individuals have a high probability of getting DI transfers in the future. Thus, they would like to accumulate earnings credit to 

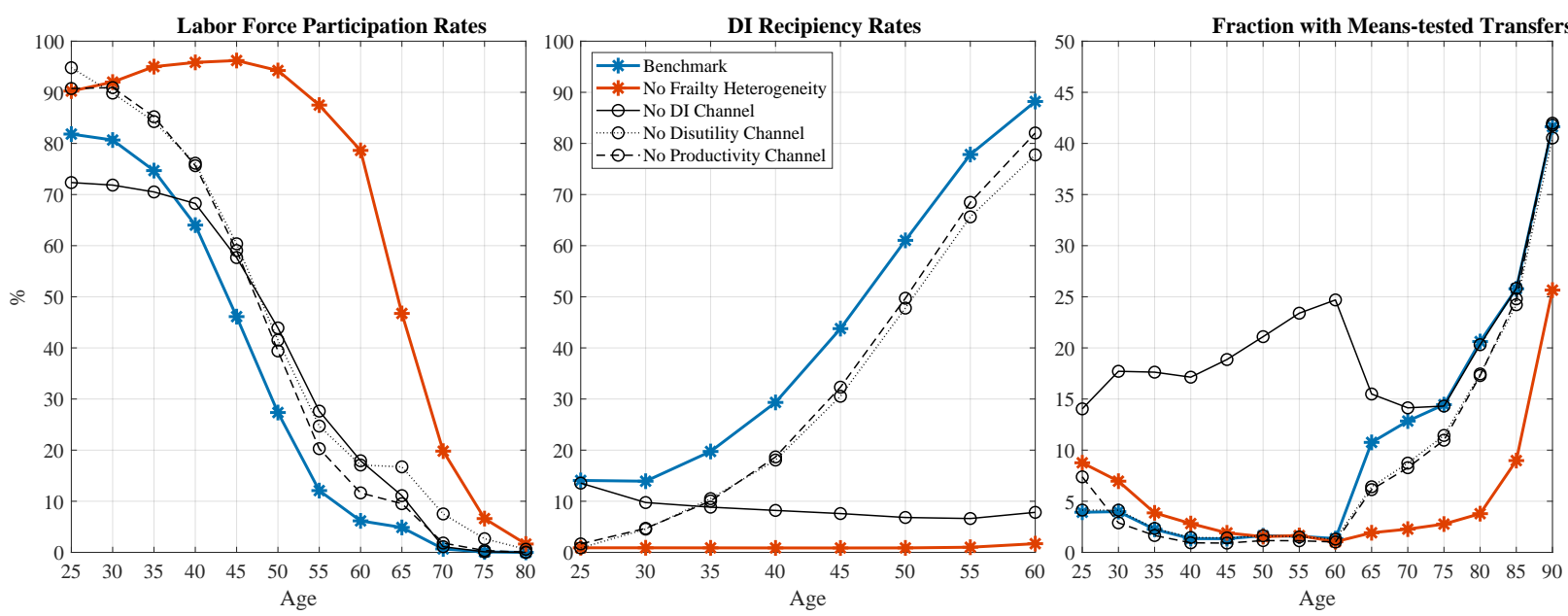

Figure 9: Labor force participation rates (left panel), DI recipiency rates (middle panel), and fraction receiving means-tested transfers (right panel) by age in the baseline economy, the no-frailty-heterogeneity economy, and counterfactuals 1-3.

raise their benefit in anticipation. Using the average frailty profile to determine DI eligibility substantially weakens this incentive as now the likelihood of a highly frail individual getting on DI is much lower. However, these individuals still suffer high disutility of work and have relatively low wages. These effects push some young frail workers in the "NFH in DI" economy out of the labor force and onto means-tested programs. Figure 9 presents the labor force participation, DI recipiency, and means-tested transfer recipiency rates for the top five percentiles of the frailty distribution in the benchmark and several of the counterfactual economies. ${ }^{52}$ Consistent with the intuition above, the left panel of the figure shows that highly frail young people in the "NFH in DI" economy are less likely to be in the labor force than those in the benchmark, while the right panel shows that they are more likely to be on means-tested transfers. Thus, by reducing the incentives for young frail individuals to work, shutting down the DI channel, reduces their labor force participation rates, increasing earnings inequality. The impact of this effect on lifetime earnings inequality is declining with age. This is because shutting down the DI channel increases labor force participation rates of frail individuals at older ages as the first panel of Figure 9 shows. Compared to young highly frail individuals, older highly frail individuals are more likely to have worked and accumulated wealth. As a result, many are not eligible for means-tested programs. In the "NFH in DI" economy, given that they have a low probability of getting on DI, they continue to work. This impact of removing the DI channel on the labor supply of older frail individuals is the primary reason for the large decline in the variance of log lifetime earnings at ages 55, 65 and 75 in the "NFH in DI" counterfactual relative to the benchmark.

The labor productivity channel is the second most important channel through which health inequality impacts lifetime earnings inequality in the model. Shutting down this

\footnotetext{
${ }^{52}$ The effects of the DI channel on the labor-force participation, DI recipiency, and mean-tested transfer recipiency rates of the other frailty groups can be seen in Section 5 of the Online Appendix. The figures show that there is little impact of removing health inequality for individuals with frailty below the 70th percentile. For those in the 70th-95th percentiles, the effects of the DI channel are similar to those in Figure 9.
} 


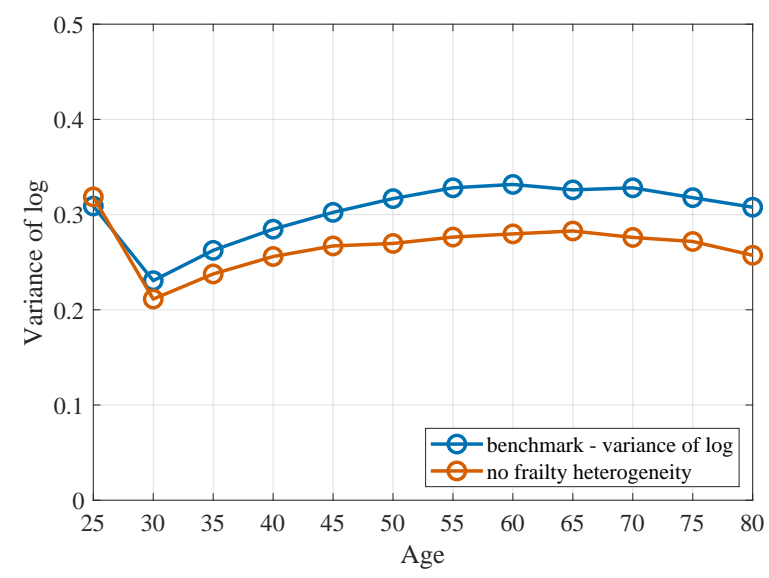

(a) Variance of log lifetime disposable income

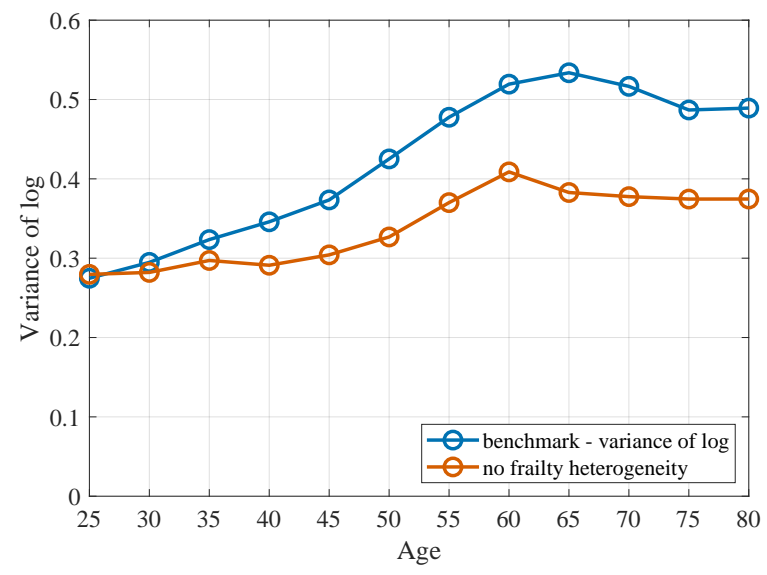

(b) Variance of log consumption

Figure 10: Panel (a) is the variance of log lifetime disposable (defined as the sum of labor earnings and transfers net of taxes). Panel (b) is the variance of log consumption. The blue line is the benchmark and the red line is the no-frailty-heterogeneity economy.

channel reduces lifetime earnings inequality at all ages. Using the average frailty profile to determine labor productivity reduces the variation in wages conditional on age. This has two effects. First, it leads directly to a reduction in earnings, and hence, lifetime earnings inequality. Second, it increases the returns from working for less educated individuals and frail college graduates which increases their labor supply. This second effect operates even for the most highly frail individuals as Figure 9 shows. ${ }^{53}$ Notice that, at nearly all ages, these individuals have higher labor force participation and lower DI and means-tested transfer recipiency rates in the "NFH in Labor Productivity" economy relative to the benchmark. ${ }^{54}$

The disutility, medical expense, and mortality channels play relatively smaller roles. The smaller role of the mortality channel is due to two offsetting effects of shutting it down. First, it increases the life expectancy of frail individuals which increases their returns to work and labor supply. This effect works to reduce lifetime earnings inequality. Second, since mortality and productivity are negatively correlated in the benchmark (due to both education and health), it raises the survival rates of individuals in the bottom of the lifetime earnings distribution relative to those in the top. This second effect, which grows with age due to the nature of mortality risk, works to increase lifetime earnings inequality.

\subsection{Alternative measures of inequality}

Our findings show that health inequality increases lifetime earnings inequality. The increase is driven by the negative impacts of poor health on the labor supply and earnings of individ-

\footnotetext{
${ }^{53}$ See Section 5 of the Online Appendix for a summary of the overall effects of shutting down each channel on labor force, DI, and means-tested program participation rates.

${ }^{54}$ Means-tested transfer recipiency rates are slightly higher for 25-29 year olds in the "NFH in Labor Productivity" economy because some young individuals who were receiving DI in the benchmark now choose to work but have such low earnings that they also qualify for means-tested transfers.
} 
uals in the bottom of the lifetime earnings distribution. This increase is offset by SSDI and means-tested transfers. However, the offset is only partial. As a result, health inequality is also a significant driver of inequality in disposable income. Figure 10a presents the variance of $\log$ lifetime disposable income by age in the benchmark and NFH economies. ${ }^{55}$ Removing health inequality reduces lifetime disposable income inequality by about 44 percent as much as it reduces lifetime earnings inequality. For instance, the variance of log lifetime earnings at age 65 falls by 30.4 percent, while the variance of log lifetime disposable income at age 65 falls by 13.3 percent. ${ }^{56}$ This finding implies that a bit more than half of the inequality in lifetime earnings due to poor health is undone through the tax and transfer system.

Interestingly, the relatively smaller impacts of health inequality on lifetime disposable income inequality do not translate into smaller impacts of health inequality on consumption inequality. Figure $10 \mathrm{~b}$ shows that removing health inequality reduces the variance of $\log$ current consumption by a similar amount as the variance of log lifetime earnings. The variance of log consumption at age 65 is 28.3 percent lower in the NFH economy as compared to the benchmark. Why are the impacts on consumption inequality so much larger than the impacts on lifetime disposable income inequality? The primary reason is that removing health inequality reduces wealth inequality. Less educated individuals in poor health in the benchmark have lower savings than less educated individuals in the NFH economy for three reasons. First, they have less income. Second, they have less incentives to accumulate wealth due to a lower life expectancy. Third, poor health (or the risk of poor health) means they are more impacted by the negative effects of the means-tested transfer program on incentives to save. ${ }^{57}$

\subsection{The value of social security disability insurance}

Our findings above indicate that health inequality is a major contributor to inequality in lifetime earnings. They also indicate that the primary channel through which health inequality generates lifetime earnings inequality is the DI program. The incentives for middle-aged frail individuals to work and accumulate labor earnings are significantly reduced by the fact that they have a high probability of obtaining DI benefits if they apply. These results suggest that one way to reduce lifetime earnings inequality is to eliminate DI. We now assess the long-run welfare implications of such a policy. ${ }^{58}$

First, consider the direct impact of removing the DI program. This is done by setting the probability of getting DI to zero and adjusting the payroll tax so that the total payroll

\footnotetext{
${ }^{55}$ Disposable income as the sum of labor earnings and transfers net of all taxes. Lifetime disposable income at each age is the sum of disposable income to date. We have done all the calculations with an alternative definition that includes capital income. The results are very similar.

${ }^{56}$ See Section 5 of the Online Appendix for a counterpart to Table 9 for lifetime disposable income and current consumption.

${ }^{57}$ It is well documented that means-tested transfer programs distort savings incentives and that their distortionary effects are larger for lower income individuals. See, for instance, Hubbard et al. (1995).

${ }^{58}$ We conduct this exercise in a model that lacks a private disability insurance market. We do this because the private disability insurance market in the U.S. is small and likely suffers from significant information frictions that impede its functioning. Only 3 percent of non-government workers have directly purchased this insurance and only 30 percent have obtained it indirectly through their employer. Hendren (2013) documents that coverage denial rates in the market are high and driven by the presence of private information.
} 
Table 11: Aggregate and welfare effects of eliminating DI

\begin{tabular}{lcccc}
\hline & Benchmark & \multicolumn{3}{c}{ No DI benefits \& tax } \\
& $(1)$ & $(2)$ & $(3)$ & $(4)$ \\
\hline Welfare - C.V. relative to benchmark (\%) & & & & \\
All & n.a. & -1.16 & -1.80 & -2.50 \\
$\quad$ HSD & n.a. & -3.14 & -3.70 & -5.81 \\
HS & n.a. & -1.81 & -2.45 & -3.22 \\
CL & n.a. & 0.74 & 0.05 & 0.09 \\
Inequality - Variance of & & & & \\
$\quad$ log lifetime earnings (at age 65) & 0.453 & 0.347 & 0.352 & 0.276 \\
log lifetime disposable income (at age 65) & 0.326 & 0.267 & 0.268 & 0.249 \\
log consumption (overall) & 0.180 & 0.183 & 0.184 & 0.163 \\
Change relative to benchmark (\%) & & & & \\
GDP & n.a. & 1.43 & 1.37 & 2.39 \\
Consumption & n.a. & 1.90 & 1.13 & 2.37 \\
Capital & n.a. & 1.43 & 1.37 & 2.39 \\
Hours & n.a. & 1.66 & 1.49 & 4.37 \\
$\quad$ GDP per hour & n.a. & -0.23 & -0.12 & -1.90 \\
Fraction (\%) & & & & \\
$\quad$ Working (25 to 64 year olds) & 87.3 & 88.6 & 88.4 & 91.1 \\
$\quad$ On DI (25 to 64 year olds) & 5.84 & 0.00 & 0.00 & 0.00 \\
On means tested transfers (all) & 4.24 & 7.43 & 7.60 & 5.03 \\
Policy Variables & & & & \\
$\quad$ Payroll tax rate (\%) & 12.4 & 11.1 & 11.1 & 11.1 \\
Consumption floor (\% of ave. earning) & 11.0 & 11.0 & 11.0 & 9.7 \\
Tax function parameter $(\lambda)$ & 0.91 & 0.91 & 0.90 & 0.91 \\
\hline
\end{tabular}

Note: Column (2) is no DI in partial equilibrium: removal of SSDI and SSI benefits and corresponding SSDI fraction of payroll tax. Columns (3) and (4) are no DI in general equilibrium with government budget balanced by adjusting the income tax and consumption floor, respectively.

tax receipt declines by exactly the amount of expenditures on the SSDI portion of benefits in the baseline. ${ }^{59}$ We refer to this experiment as partial equilibrium, since we do not attempt to balance the government budget. The second column of Table 11 shows the steady-state (long-run) welfare and aggregate implications. Notice that, consistent with the findings above, eliminating the DI program significantly reduces inequality in earnings and income. The variances of age-65 log lifetime earnings and disposable income fall by 23.4 and 18.1 percent, respectively. It also increases aggregate consumption, as well as, aggregate GDP. Yet, it does not reduce consumption inequality and it is ex ante welfare reducing. The decline in welfare, measured as the equivalent change in lifetime consumption, is 1.16 percent. The decline is driven by the welfare losses of less educated individuals. Whereas college graduates

\footnotetext{
${ }^{59}$ The initial distribution across employment states is also changed by moving DI beneficiaries to nonemployed.
} 
benefit, on net, from this change (mostly due to lower taxes), both high school dropouts and graduates are worse off with welfare declines equivalent to 3.14 and 1.81 percent of lifetime consumption, respectively. For these less educated individuals, the DI program provides valuable insurance against their relatively higher risk of becoming severely frail and incurring high disutility from work together with lower wages, and the insurance is heavily subsidized by college graduates.

Why does the variance of log consumption slightly increase when DI is removed? Removing DI leaves individuals more exposed to the risk of becoming highly frail and incurring high disutility from work. This increased risk exposure generates two responses that have opposite effects on consumption inequality. Some individuals offset the increased risk by working and saving more which tends to reduce consumption inequality. Others offset it by relying more heavily on means-tested transfers which tends to increase it. In particular, middle-aged frail workers increase their labor supply as the cost of not working has gone up and they have already accumulated too much wealth to be eligible for means-tested transfers. Their response drives the rise in the aggregate labor force participation rate shown in Table 11. In contrast, the labor force participation rates of younger frail workers, under age 40, decline. This happens because removing the DI program has a similar effect on young frail individuals as using the average frailty profile to determine DI eligibility. That is, it substantially reduces their incentive to work and accumulate lifetime earnings and wealth in anticipation of receiving DI transfers during middle-age. Instead, they reply more heavily on means-tested transfers which generates the rise in means-tested transfer recipiency rates reported in Table 11.

The rise in the means-tested transfer recipiency rates generates an increase in government expenditures. To show the impact of closing this fiscal gap on our welfare calculations, we perform two additional experiments. In the first experiment, we finance the expansion of means-tested programs by raising federal income taxes (by reducing parameter $\lambda$ in the HSV tax function). The results of this experiment are reported in column (3) of Table 11. Alternatively, we close the gap by reducing the level of means-tested transfer benefits (by reducing consumption floor parameter $\bar{c}$ ). The results for this experiment are reported in column (4). These general equilibrium results reinforce our initial finding. Eliminating the DI program, despite reducing inequality in earnings and income and generating sizable gains in aggregate consumption and GDP, is not welfare improving. Welfare losses from eliminating the program are even larger in general equilibrium. If we close the fiscal gap by increasing income tax rates, ex ante welfare falls by 1.80 percent. If we close the gap instead by reducing the means-tested consumption floor, it falls by 2.50 percent. In both cases, welfare losses are particularly large for high school dropouts whose welfare declines by 3.70 or 5.81 percent depending on which rule is used to clear the government budget.

Before they know their education type, individuals in our model prefer an economy with a DI program. However, once education is known, only the non-college individuals prefer to live with DI. The reason for this result is that DI is both an insurance program and a redistribution program. College-educated workers who have higher earnings and better health are more likely to work and less likely to use DI. Consequently, their payroll and income taxes disproportionately finance this program. How much of the welfare benefits of the DI program for the non-college groups is due to insurance, and how much is due to redistribution? How much would college graduates value a DI program that did not 
Table 12: Welfare effects of a DI program without redistribution across education groups

\begin{tabular}{lcccc}
\hline & Benchmark & No DI & \multicolumn{2}{c}{ No redistribution } \\
& $(1)$ & $(2)$ & $(3)$ & $(4)$ \\
\hline Welfare - C.V. relative to benchmark (\%) & n.a. & -1.16 & -0.2 & -1.61 \\
HSD & n.a. & -3.14 & -1.99 & -3.21 \\
HS & n.a. & -1.81 & -0.54 & -1.93 \\
CL & n.a. & 0.74 & 1.08 & -0.42 \\
\% working (25 to 64 year olds) & 87.3 & 88.6 & 87.1 & 86.8 \\
HSD & 76.0 & 77.8 & 75.1 & 74.5 \\
HS & 85.3 & 86.9 & 85.2 & 84.7 \\
CL & 93.8 & 94.5 & 94.0 & 93.8 \\
\% on DI $(25$ to 64 year olds) & 5.84 & 0.00 & 5.88 & 5.95 \\
HSD & 13.21 & 0.00 & 13.45 & 13.57 \\
HS & 7.42 & 0.00 & 7.45 & 7.55 \\
CL & 1.12 & 0.00 & 1.10 & 1.13 \\
\% on means tested transfers & 4.24 & 7.43 & 4.35 & 4.66 \\
HSD & 7.98 & 16.47 & 8.72 & 9.17 \\
HS & 4.20 & 8.34 & 4.34 & 4.71 \\
CL & 3.10 & 3.30 & 2.98 & 3.14 \\
DI payroll tax rate $(\%)$ & & & & \\
HSD & 12.4 & 11.1 & 14.5 & 14.6 \\
HS & 12.4 & 11.1 & 12.9 & 12.9 \\
CL & 12.4 & 11.1 & 11.4 & 11.4 \\
Tax function parameter $(\lambda)$ & 0.91 & 0.91 & 0.91 & 0.89 \\
\hline
\end{tabular}

Note: Column (2) is the 'No DI' partial equilibrium economy also reported in column (2) of Table 11. Column (3) is no redistribution in partial equilibrium: DI benefits of each education group are paid for by education-specific payroll taxes. Columns (4) is no redistribution in general equilibrium: government budget is balanced by adjusting the income tax.

feature redistribution across education groups? To answer these questions, we consider a counterfactual DI system that requires outlays to be self-financing within each education group. In this counterfactual system, DI benefits are financed by education-specific payroll taxes. Naturally, in this system, the payroll taxes of high school dropouts go up and those of college graduates go down. As before, we report a partial equilibrium outcome in which the government budget is not balanced and a general equilibrium outcome in which we adjust the level of income taxes (by adjusting parameter $\lambda$ ) to balance the government budget.

Column (3) of Table 12 reports the results for the partial equilibrium experiment. Welfare is calculated as a consumption equivalent variation relative to the benchmark. These numbers demonstrate the welfare effects of eliminating redistribution across education groups in the DI program. Comparing them to the welfare effects of removing DI altogether, provided in column (2), we can disentangle the insurance value of DI for each education group 
from the redistribution value. For example, when there is no redistribution, welfare falls for high school dropouts by about 2 percent as compared to a 3.14 percent loss when the DI program is removed completely. These losses indicate that two-thirds of the value of DI for high school dropouts is due to the redistribution aspect of the program and one-third, or 1.18 percent of lifetime consumption, is due to the insurance value. It is the opposite for high school graduates: about one-third (0.54 percent) is due to redistribution and about two-thirds (1.27 percent) is due to the insurance value. Obviously, for college graduates the redistribution aspect of the DI program is a cost. Removing it increases their welfare by 1.08 percent. But, they would rather have a separate DI program than not have one at all. The value they place on such an arrange is equivalent to 0.34 percent of consumption.

The general equilibrium results from removing redistribution by education are reported in column (4) of Table 12. Welfare losses are larger than in partial equilibrium due to the increase in income taxes. Comparing column (1) to column (3), notice that when redistribution is removed the fraction of high school dropouts who work goes down by 1 percentage point and almost all of these workers claim means tested transfers. Therefore, to balance the government budget income taxes have to go up. But higher income taxes push even more high school dropouts out of the labor force and onto means-tested programs. Eventually, in the new equilibrium everyone's taxes are higher and labor supply is lower. The effect of higher income taxes more than offset the gains from removing redistribution in DI for college graduates. As a result the reform leaves all education groups worse off relative to the benchmark.

Given that we find that the DI program is ex ante welfare improving, we now consider two additional sets of experiments that explore whether the current scale of the program is too low or too high. In the first set, we reduce DI benefits by 10 percent along with an appropriate adjustment in payroll taxes. We perform this experiment with and without balancing the government budget. The second set is the same as the first one except that we increase DI benefits by 10 percent. The results, which are reported in Table 13, show that from an ex ante welfare perspective the current DI program may not be generous enough. First, a 10 percent decline in benefits leads to welfare losses which are sizable in comparison to the welfare changes reported in Table 11. For example, the overall ex ante welfare loss from cutting the program by 10 percent is 0.44 percent, more than one third of the 1.16 percent welfare loss from cutting the program all together. Second, even when the tax implications of balancing the government budget are accounted for, expanding benefits by 10 percent increases the welfare of high school dropouts and graduates by significantly more than the losses it generates for the college graduates. Overall, such a policy raises ex ante welfare by 0.29 percent.

Finally, notice in Table 13 that cutting DI benefits reduces the fraction of individuals receiving means-tested transfers, while raising benefits increases it. This may be surprising given that eliminating the DI program all together increases means-tested transfer recipiency rates. Recall that the primary reason that recipiency rates rise when the DI program is removed is because frail individuals under age 45 have a reduced incentive to work and accumulate SSDI credits. While eliminating DI increases the means-tested transfer recipiency rates of this group, cutting DI benefits by 10 percent decreases them. With lower (but still positive) DI benefit levels, these individuals have a reduced incentive to exit the labor force and collect MTSI transfers while trying to get on DI. Consequently, they have higher labor 
Table 13: Aggregate and welfare effects of marginal changes to DI

\begin{tabular}{lccccc}
\hline & Benchmark & \multicolumn{2}{c}{ Cut DI benefit by $10 \%$} & \multicolumn{2}{c}{ Raise DI benefit by $10 \%$} \\
& $(1)$ & $(2)$ & $(3)$ & $(4)$ & $(5)$ \\
\hline Welfare - C.V. relative to benchmark (\%) & & & & & \\
$\quad$ All & n.a. & -0.44 & -0.35 & 0.37 & 0.29 \\
$\quad$ HSD & n.a. & -1.17 & -1.09 & 1.06 & 0.99 \\
$\quad$ n.a. & -0.57 & -0.49 & 0.50 & 0.41 \\
$\quad$ CL & n.a. & 0.08 & 0.17 & -0.10 & -0.19 \\
Change relative to benchmark (\%) & & & & & \\
$\quad$ GDP & n.a. & 0.26 & 0.26 & -0.32 & -0.33 \\
$\quad$ nonsumption & n.a. & 0.24 & 0.34 & -0.30 & -0.40 \\
$\quad$ napital & n.a. & 0.26 & 0.26 & -0.32 & -0.33 \\
$\quad$ Labor input & n.a. & 0.49 & 0.26 & -0.32 & -0.33 \\
$\quad$ nours & n.a. & -0.23 & -0.24 & -0.63 & -0.66 \\
$\quad$ GDP per hour & & & & & 0.31 \\
Fraction of population $(\%)$ & 87.28 & 87.73 & 87.75 & 86.69 & 86.66 \\
$\quad$ Working & 5.84 & 5.54 & 5.53 & 6.21 & 6.22 \\
$\quad$ On DI & 4.24 & 4.23 & 4.22 & 4.43 & 4.45 \\
$\quad$ On means tested transfers & & & & & \\
Policy Variables & 12.4 & 12.2 & 12.2 & 12.6 & 12.6 \\
$\quad$ Payroll tax rate $(\%)$ & 11.0 & 11.0 & 11.0 & 11.0 & 11.0 \\
$\quad$ Consumption floor (\% of ave. earning) & 0.91 & 0.91 & 0.91 & 0.91 & 0.91 \\
$\quad$ Tax function parameter $(\lambda)$ & & & & & \\
\hline
\end{tabular}

Note: Columns (2) and (4) are marginal DI changes in partial equilibrium: only the payroll tax adjusts by the amount of the change in SSDI benefits. Column (3) and (5) are general equilibrium with the government budget balanced by adjusting the income tax.

force participation rates and lower means-tested transfer recipiency rates both when young and during retirement. This same effect, operating in reverse, is also the primary reason that raising DI benefits by 10 percent raises means-tested transfer recipiency rates. Higher DI benefits increase the incentives for frail individuals to exit the labor force at relatively younger ages, increasing their likelihood of means-tested transfer eligibility both when young and after retirement. These findings highlight how the subtle interactions between these two programs make it difficult to predict how changes to one will impact the size of the other. ${ }^{60}$

\section{Conclusion}

In this paper, we document empirically that declines in health reduce labor productivity and the probability of labor force participation. The effects are concentrated in less educated individuals and those already in poor health suggesting that health inequality may be an important source of lifetime earnings inequality. Using a structural model, we demonstrate that this is indeed the case: 30 percent of the variation in lifetime earnings at age 65 is due to the fact that individuals in the United States face risky and heterogeneous lifecycle health profiles. A decomposition exercise shows that the impact of poor health on access to social security disability benefits is the most important factor driving our results. In other words,

\footnotetext{
${ }^{60}$ Low and Pistaferri (2015) document similar non-monotonic effects of increasing the generosity of meanstested food stamps on DI application rates.
} 
the primary reason why individuals in poor health have low lifetime earnings is because they have a high likelihood of obtaining social security disability benefits. The negative effects of poor health on labor productivity also play an important role. Interestingly, we find that the disutility effects of working while in poor health are not an important driver of earnings inequality due to poor health. These findings indicate that the social security program is an important contributor to lifetime earnings inequality. Despite this, we document that it is ex ante welfare improving and, if anything, should be expanded.

\section{References}

AddA, J., J. BANKS AND H.-M. Von GAUdECKER, "The impact of income shocks on health: evidence from cohort data," Journal of the European Economic Association 7 (2009), 1361-1399. 6

Aizawa, N., S. Kim And S. Rhee, "Labor Market Screening and Social Insurance Program Design for the Disabled," (2020). 5

Al-Sadoon, M. M., S. Jiménez-Martín, J. M. Labeaga et Al., "Simple methods for consistent estimation of dynamic panel data sample selection models," Technical Report, 2019. 3, 25

Apouey, B. And A. E. Clark, "Winning big but feeling no better? The effect of lottery prizes on physical and mental health," Health economics 24 (2015), 516-538. 6

Arellano, M. And S. Bond, "Some Tests of Specification for Panel Data: Monte Carol Evidence and and Application to Employment Equations," The Review of Economic Studies 58 (1991), 277-297. 10

Arellano, M. AND O. Bover, "Another look at the instrumental variable estimation of error-components models," Journal of econometrics 68 (1995), 29-51. 10

Attanasio, O. P., "Consumption," Handbook of macroeconomics 1 (1999), 741-812. 24

Au, D. W. H., T. F. Crossley and M. Schellhorn, "The effect of health changes and long-term health on the work activity of older Canadians," Health economics 14 (2005), 999-1018. 6

Autor, D. H. And M. G. Duggan, "The rise in the disability rolls and the decline in unemployment," The Quarterly Journal of Economics 118 (2003), 157-206. 5

Beck, T., R. Levine And N. Loayza, "Finance and the Sources of Growth," Journal of financial economics 58 (2000), 261-300. 10

Bell, F. C. And M. L. Miller, "Life tables for the United States social security area," Social Security Administration Publications (2005). 23 
Benabou, R., "Tax and Education Policy in a Heterogeneous Agent Economy: What Levels of Redistribution Maximize Growth and Efficiency?," Econometrica 70(2) (2002), 481-517. 30

Black, S. E., P. J. Devereux and K. G. Salvanes, "Losing heart? The effect of job displacement on health," ILR Review 68 (2015), 833-861. 6

Blundell, R. AND S. Bond, "Initial conditions and moment restrictions in dynamic panel data models," Journal of econometrics 87 (1998), 115-143. 3, 10

—, "GMM estimation with persistent panel data: an application to production functions," Econometric reviews 19 (2000), 321-340. 10

Blundell, R., M. C. Dias, J. Britton and E. French, "The impact of health on labor supply near retirement," Journal of Human Resources (2020), 1217-9240R4. 5

Blundell, R. And T. MaCurdy, "Labor supply: A review of alternative approaches," in Handbook of labor economicsvolume 3 (Elsevier, 1999), 1559-1695. 24

Bond, S. And C. MEghir, "Dynamic investment models and the firm's financial policy," The Review of Economic Studies 61 (1994), 197-222. 10

Bond, S. R., "Dynamic panel data models: a guide to micro data methods and practice," Portuguese economic journal 1 (2002), 141-162. 11

Bound, J., "The Health and Earnings of Rejected Disability Insurance Applicants," The American Economic Review (1989), 482-503. 5, 32

Bound, J., M. Schoenbaum, T. R. Stinebrickner and T. Waidmann, "The dynamic effects of health on the labor force transitions of older workers," Labour Economics 6 (1999), 179-202. 6

Braun, R. A., K. A. Kopecky and T. Koreshkova, "Old, sick, alone, and poor: A welfare analysis of old-age social insurance programmes," The Review of Economic Studies 84 (2017), 580-612. 5

Browning, M., A. Moller Dano And E. Heinesen, "Job displacement and stressrelated health outcomes," Health economics 15 (2006), 1061-1075. 6

Capatina, E., "Life-cycle effects of health risk," Journal of Monetary Economics 74 (2015), 67-88. 5, 24

Capatina, E., M. Keane, S. Maruyama et Al., "Health Shocks and the Evolution of Earnings over the Life-Cycle," Technical Report, 2020. 5

Caselli, F., G. Esquivel And F. Lefort, "Reopening the convergence debate: a new look at cross-country growth empirics," Journal of economic growth 1 (1996), 363-389. 10 
Cesarini, D., E. Lindqvist, R. Östling and B. Wallace, "Wealth, health, and child development: Evidence from administrative data on Swedish lottery players," The Quarterly Journal of Economics 131 (2016), 687-738. 6

Conti, G., J. Heckman and S. Urzua, "The early origins of the education-health gradient. Under revision," Perspectives on Psychological Science 4 (2010a). 6

6

Cutler, D. M., A. Lleras-Muney and T. Vogl, "Socioeconomic Status and Health: Dimensions and Mechanisms," in S. Glied and P. C. Smith, eds., The Oxford Handbook of Health Economicschapter 7 (Oxford: Oxford University Press, 2011). 6

Dalgaard, C.-J. And H. Strulik, "Optimal Aging and Death: Understanding the Preston Curve," Journal of the European Economic Association 12 (2014), 672-701. 2

De Nardi, M., E. French And J. B. Jones, "Why do the Elderly Save? The Role of Medical Expenses," Journal of Political Economy 118 (2010), 37-75. 5

De Nardi, M., S. Pashchenko and P. Porapakkarm, "The Lifetime Costs of Bad Health," Working Paper, 2017. 5, 24

Dobkin, C., A. Finkelstein, R. Kluender And M. J. Notowidigdo, "The economic consequences of hospital admissions," American Economic Review 108 (2018), 308-52. 6

Eliason, M. And D. StorRie, "Job loss is bad for your health-Swedish evidence on cause-specific hospitalization following involuntary job loss," Social science $\mathscr{E} \mathfrak{3}$ medicine 68 (2009), 1396-1406. 6

Finkelstein, A., E. F. Luttmer And M. J. Notowidigdo, "What good is wealth without health? The effect of health on the marginal utility of consumption," Journal of the European Economic Association 11 (2013), 221-258. 24

French, E., "The effects of health, wealth, and wages on labour supply and retirement behaviour," The Review of Economic Studies 72 (2005), 395-427. 5, 24

French, E. And J. B. Jones, "Health, health insurance, and retirement: a survey," Annual Review of Economics 9 (2017), 383-409. 5

French, E. AND J. Song, "The effect of disability insurance receipt on labor supply," American economic Journal: economic policy 6 (2014), 291-337. 4, 5, 28, 29, 31, 32

García Gómez, P. AND Á. LóPez Nicolás, "Health shocks, employment and income in the Spanish labour market," Health economics 15 (2006), 997-1009. 6

García-Gómez, P., H. Van Kippersluis, O. O’Donnell and E. Van Doorslaer, "Long-term and spillover effects of health shocks on employment and income," Journal of Human Resources 48 (2013), 873-909. 6 
Gathmann, C., K. Huttunen, L. Jernström, L. SÄÄksvuori and R. Stitzing, "In sickness and in health: job displacement and health spillovers in couples," (2021). 6

GifForD, B., "Temporarily disabled workers account for a disproportionate share of health care payments," Health Affairs 36 (2017), 245-249. 18

Goggins, W. B., J. Woo, A. Sham And S. C. Ho, "Frailty index as a measure of biological age in a Chinese population," The Journals of Gerontology Series A: Biological Sciences and Medical Sciences 60 (2005), 1046-1051. 8

Gomme, P. And P. Rupert, "Theory, Measurement and Calibration of Macroeconomic Models," Journal of Monetary Economics 54 (2007), 460-497. 30, 31

Guner, N., R. Kaygusuz and G. Ventura, "Income taxation of US households: Facts and parametric estimates," Review of Economic Dynamics 17 (2014), 559-581. 30

Guvenen, F., "An Empirical Investigation of Labor Income Processes," Review of Economic Dynamics 12 (2009), 58-79. 26

Guvenen, F., G. Kaplan, J. Song and J. Weidner, "Lifetime incomes in the United States over six decades," Technical Report, National Bureau of Economic Research, 2017. 33

Heathcote, J., K. Storesletten and G. Violante, "Optimal Tax Progressivity: An Analytical Framework," Quarterly Journal of Economics 132(4) (2017), 1693-1754. 30

Heckman, J. J., J. E. Humphries and G. Veramendi, "Returns to education: The causal effects of education on earnings, health, and smoking," Journal of Political Economy 126 (2018), S197-S246. 6

Heinesen, E. And C. KolodziejCzyK, "Effects of breast and colorectal cancer on labour market outcomes-average effects and educational gradients," Journal of health economics 32 (2013), 1028-1042. 6

Hendren, N., "Private Information and Insurance Rejections," Econometrica 81 (2013), 1713-1762. 40

Hoechle, D., M. Schmid, I. Walter and D. Yermack, "How much of the diversification discount can be explained by poor corporate governance?," Journal of Financial Economics 103 (2012), 41-60. 10

Holtz-Eakin, D., W. Newey and H. S. Rosen, "Estimating vector autoregressions with panel data," Econometrica: Journal of the Econometric Society (1988), 1371-1395. 10

Hong, J. H. And J.-V. Ríos-Rull, "Life insurance and household consumption," American Economic Review 102 (2012), 3701-30. 31

Hosseini, R., K. Kopecky And K. Zhao, "The Evolution of Health over the Life Cycle," Review of Economic Dynamics (forthcoming). 2, 3, 7, 26 
Hubbard, R. G., J. Skinner And S. P. Zeldes, "Precautionary Savings and Social Insurance," Journal of Political Economy 103 (1995), 360-399. 40

Imrohoroglu, A. And K. Zhao, "The Chinese Saving Rate: Long-Term Care Risks, Family Insurance, and Demographics," Journal of Monetary Economics 96 (2018). 5

JEON, S.-H., "The long-term effects of cancer on employment and earnings," Health economics 26 (2017), 671-684. 6

Jones, J. B. AND Y. Li, "The effects of collecting income taxes on social security benefits," Journal of Public Economics 159 (2018), 128-145. 20

Junna, L., H. Moustgaard, K. Huttunen and P. Martikainen, "The association between unemployment and mortality: a cohort study of workplace downsizing and closure," American journal of epidemiology 189 (2020), 698-707. 6

Keefe, V., P. Reid, C. Ormsby, B. Robson, G. Purdie, J. Baxter and N. K. I. INCORPORATED, "Serious health events following involuntary job loss in New Zealand meat processing workers," International Journal of Epidemiology 31 (2002), 1155-1161. 6

KIM, S. AND S. RHEE, "Understanding the aggregate effects of disability insurance," (2020). 5

KitaO, S., "A life-cycle model of unemployment and disability insurance," Journal of Monetary Economics 68 (2014), 1-18. 5

Kopecky, K. And T. Koreshkova, "The Impact of Medical and Nursing Home Expenses on Savings," American Economic Journal: Macroeconomics 6 (2014), 29-72. 5, 30

Kulminski, A., A. Yashin, K. Arbeev, I. Akushevich, S. Ukraintseva, K. Land And K. MAnton, "Cumulative index of health disorders as an indicator of agingassociated processes in the elderly: results from analyses of the National Long Term Care Survey," Mechanisms of ageing and development 128 (2007a), 250-258. 8

Kulminski, A. M., S. V. Ukraintseva, I. V. Akushevich, K. G. Arbeev and A. I. YAshin, "Cumulative index of health deficiencies as a characteristic of long life," Journal of the American Geriatrics Society 55 (2007b), 935-940. 8

LEnharT, O., "The effects of health shocks on labor market outcomes: evidence from UK panel data," The European Journal of Health Economics 20 (2019), 83-98. 6

Low, H. AND L. Pistaferri, "Disability insurance and the dynamics of the incentive insurance trade-off," American Economic Review 105 (2015), 2986-3029. 5, 25, 26, 45

Lundborg, P., M. Nilsson And J. Vikström, "Heterogeneity in the impact of health shocks on labour outcomes: evidence from Swedish workers," Oxford Economic Papers 67 (2015), 715-739. 6 
Maestas, N., K. J. Mullen And A. Strand, "Does disability insurance receipt discourage work? Using examiner assignment to estimate causal effects of SSDI receipt," American economic review 103 (2013), 1797-1829. 5, 17, 32

Meer, J., D. L. Miller And H. S. Rosen, "Exploring the health-wealth nexus," Journal of health economics 22 (2003), 713-730. 6

Michaud, A. And D. Wiczer, "The Disability Option: Labor Market Dynamics with Macroeconomic and Health Risks," (2017). 5

Michaud, P.-C. And A. VAn Soest, "Health and wealth of elderly couples: Causality tests using dynamic panel data models," Journal of health economics 27 (2008), 1312-1325. 10

Mitnitski, A., X. Song, I. Skoog, G. A. Broe, J. L. Cox, E. Grunfeld And K. Rockwood, "Relative fitness and frailty of elderly men and women in developed countries and their relationship with mortality," Journal of the American Geriatrics Society 53 (2005), 2184-2189. 8

Mitnitski, A. B., J. E. Graham, A. J. Mogilner and K. Rockwood, "Frailty, fitness and late-life mortality in relation to chronological and biological age," BMC geriatrics 2 (2002), 1. 7

Mitnitski, A. B., A. J. Mogilner And K. Rockwood, "Accumulation of deficits as a proxy measure of aging," The Scientific World Journal 1 (2001), 323-336. 7, 8

Mitnitski, A. B., X. Song And K. Rockwood, "The estimation of relative fitness and frailty in community-dwelling older adults using self-report data," The Journals of Gerontology Series A: Biological Sciences and Medical Sciences 59 (2004), M627-M632. 8

NiCKELl, S., "Biases in dynamic models with fixed effects," Econometrica: Journal of the Econometric Society (1981), 1417-1426. 10

NygaARD, V. M., "Causes and Consequences of Life Expectancy Inequality," Technical Report, Mimeo, University of Houston, 2021. 5

Ozcan, S., "Preventive vs. Curative Medicine: A Macroeconomic Analysis of Health Care over the Life Cycle," , 2013. 5

Pashchenko, S. And P. Porapakkarm, "Work incentives of Medicaid beneficiaries and the role of asset testing," International Economic Review 58 (2017), 1117-1154. 24

- "Reducing medical spending of the publicly insured: the case for a cash-out option," American Economic Journal: Economic Policy 11 (2019), 390-426. 24

Pelkowski, J. M. And M. C. Berger, "The impact of health on employment, wages, and hours worked over the life cycle," The Quarterly Review of Economics and Finance 44 (2004), 102-121. 6 
Pohl, V., C. Neilson And F. Parro, "The Effect of Health Shocks on Employment: Evidence From Accidents in Chile," (2013). 6

Prados, M. J., "Health And Earnings Inequality Over The Life Cycle And The Redistributive Potential Of Health Policies," University of Southern California Working Paper, 2017. 5

RASCHKE, C., "Unexpected windfalls, education, and mental health: evidence from lottery winners in Germany," Applied Economics 51 (2019), 207-218. 6

Rockwood, K., M. Andrew And A. Mitnitski, "A comparison of two approaches to measuring frailty in elderly people," The Journals of Gerontology Series A: Biological Sciences and Medical Sciences 62 (2007), 738-743. 8

Rockwood, K. AND A. Mitnitski, "Frailty in relation to the accumulation of deficits," The Journals of Gerontology Series A: Biological Sciences and Medical Sciences 62 (2007), $722-727.8$

Roodman, D., "A note on the theme of too many instruments," Oxford Bulletin of Economics and statistics 71 (2009), 135-158. 11

Schaller, J. AND A. H. Stevens, "Short-run effects of job loss on health conditions, health insurance, and health care utilization," Journal of health economics 43 (2015), 190-203. 6

Schünemann, J., H. Strulik And T. Trimborn, "The gender gap in mortality: How much is explained by behavior?," Journal of Health Economics 54 (2017a), 79-90. 2

— - "Going from bad to worse: Adaptation to poor health spending, longevity, and the value of life," Journal of Economic Behavior \& Organization 140 (2017b), 130-146. 2

Searle, S., A. Mitnitski, E. Gahbauer, T. Gill and K. Rockwood, "A standard procedure for creating a frailty index," BMC Geriatrics 8 (2008), 1.8

Smith, J. P., "Healthy bodies and thick wallets: the dual relation between health and economic status," Journal of Economic perspectives 13 (1999), 145-166. 6

(2004), 108-132. 6

Suen, R., "Technological Advance and the Growth in Health Care Spending," , 2006. 5

Sullivan, D. AND T. Von WACHTER, "Job displacement and mortality: an analysis using administrative data," The Quarterly Journal of Economics 124 (2009), 1265-1306. 6

Von Wachter, T., J. Song And J. Manchester, "Trends in employment and earnings of allowed and rejected applicants to the social security disability insurance program," American economic review 101 (2011), 3308-29. 5, 32 
Whited, T. M., "Investment and financial asset accumulation," Journal of Financial Intermediation 1 (1991), 307-334. 10

Wintoki, M. B., J. S. Linck And J. M. Netter, "Endogeneity and the dynamics of internal corporate governance," Journal of Financial Economics 105 (2012), 581-606. 10

Woo, J., W. Goggins, A. Sham And S. Ho, "Social determinants of frailty," Gerontology $51(2005), 402-408.8$

Wooldridge, J. M., Econometric analysis of cross section and panel data (MIT press, 2010). 10

Zhaо, K., "Social Security and the Rise in Health Spending," Journal of Monetary Economics 64 (2014), 21-37. 5 